\title{
Morphing applications in automobiles: a review
}

\section{R. Anumodh, Balbir Singh* and Mohammad Zuber}

Department of Aeronautical and Automobile Engineering,

Manipal Institute of Technology,

Manipal Academy of Higher Education,

576104, Manipal, India

Email: anumodhrajan@gmail.com

Email: balbir.s@manipal.edu

Email: mohammad.zuber@manipal.edu

${ }^{*}$ Corresponding author

\begin{abstract}
Morphing structures are structures that alter their shape and size upon application of a stimulus. This field has been of interest to numerous researchers all over the world due to its advantages over conventionally used materials. Most reported morphing studies are confined to aerospace applications and studies conducted specifically for automotive applications are limited. This paper discusses morphing technology applications in automobiles particularly with popularly used smart materials like Shape Memory Polymer, Shape Memory Alloy, Elastomers, and others. It also addresses systems such as sensors and actuators required for morphing structures to function. Some morphing applications in an automobile have been covered. Some research in the morphing of aerostructures can be incorporated into the automotive industry, so an attempt is made to correlate the findings of aerospace research to potential automotive applications.
\end{abstract}

Keywords: morphing; shape memory alloy; shape memory polymer; actuators; smart materials; piezoelectric; elastomers; automobiles.

Reference to this paper should be made as follows: Anumodh, R., Singh, B. and Zuber, M. (2021) 'Morphing applications in automobiles: a review', Int. J. Vehicle Design, Vol. 85, No. 1, pp.1-31.

Biographical notes: R. Anumodh received his Master's in Automobile Engineering from Manipal Academy of Higher Education. He is currently working as an engineer in Volvo Group Pvt. Ltd., India.

Balbir Singh is currently a Researcher at the Department of Aerospace Engineering, Faculty of Engineering, Universiti Putra Malaysia and Senior Assistant Professor at Department of Aeronautical and Automobile Engineering, Manipal Institute of Technology, Manipal Academy of Higher Education, India.

Mohammad Zuber received his $\mathrm{PhD}$ in Aerospace Engineering from Universiti Sains Malaysia. He is currently working as an Associate Professor at Department of Aeronautical and Automobile Engineering, Manipal Institute of Technology, Manipal Academy of Higher Education, India. 


\section{Introduction}

In the last few years, the automotive sector has witnessed tremendous development. During the past couple of decades, shape-changing structures or morphing structures have seen the considerable interest of researchers around the world. However, though several morphing research studies are being developed in the aerospace field, this is yet to be replicated in the automotive industry. Morphing can give way to new materials and mechanisms which, along with many other advantages, can replace traditional methods resulting in vehicles with reduced weight, better aesthetics, and improved aerodynamic efficiency. The major requirements for any morphing automobile structure would be an appropriate morphing skin, deformable substructure, and actuators. Using traditional electric or hydraulic actuators, these flexible structures can morph into different forms.

Morphing structures have the potential to simplify construction and reduce design mass, making them a perfect fit for the automotive industry. BMW's GINA concept shown in Figure 1 was one of the first concepts developed by a major automaker that demonstrated that morphing is possible in cars and its manufacturability in an aesthetically pleasing and aerodynamically superior manner. It had a flexible, translucent, and water-resistant polyurethane-coated skin (Pagitz and Bold, 2013) that allowed the headlights and tail-lights to be integrated in a new way. There was a wire framework in the frame which extended under the skin. Hydraulic and electric actuators were used wherever flexibility was necessary. Another idea that introduced morphing was the Hiriko, as seen in Figure 2. It is a two-seater urban electric car that could fold itself into a shorter length of $1.5 \mathrm{~m}$ from its driving length of $2.5 \mathrm{~m}$ to aid parking. This vehicle concept was based on the CityCar project by the Massachusetts Institute of Technology ("Reinventing the automobile: personal urban mobility for the 21st century", 2013; Zhou et al., 2013). There are several examples of morphing technology adaptation in the aeronautical sector such as in MIG-23 and the XB-70 but studies and implementation in road vehicles have not gained much attraction.

In this review, readers are introduced to the transformation of automobiles, particularly with the use of smart materials. The focus is on the use of smart materials in automobiles for morphing skins and actuators. An attempt has been made to correlate morphing studies in the aerospace industry and their future applications in the automotive field, as there are several studies related to structural morphing for the aerospace industry.

The review includes sections relating to Morphing skin and actuator applications of smart materials. Some of the significant smart materials have been discussed for morphing skins including 'shape memory polymer', elastomers, 'shape memory alloy', etc. The requirements of shape morphing structures and shape monitoring have been discussed in brief. Applications of morphing technology have been identified in key automotive areas including aerodynamics, interiors and seating, wheels, body panels, styling, and protection. There are downsides to growing technology, and so this review also highlights the disadvantages of morphing smart materials.

In the past, few studies have been conducted around automotive morphing structures. Previous research such as Daynes and Weaver (2013) concentrated on the structural aspects of morphing structures. The authors also offered fascinating insights into the tailoring of material level rigidity and vehicle morphing mechanisms such as airfoils, ducts, etc. Chopra's study focused on smart actuators, sensors, integrated systems, and potential future research requirements (Chopra, 2002). 
Figure 1 BMW GINA concept (see online version for colours)

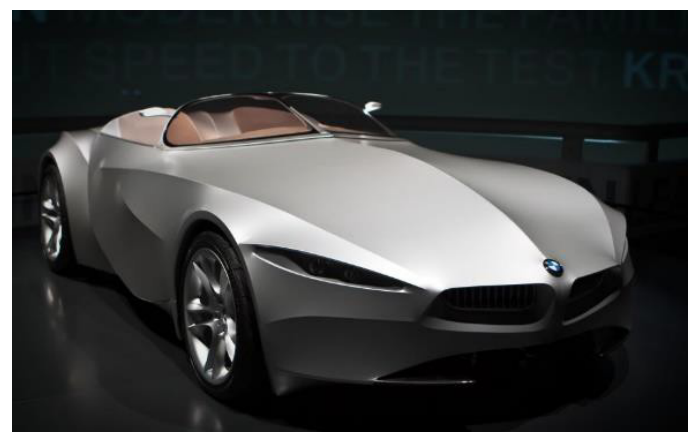

Image courtesy: ravas51 (https://commons.wikimedia.org/wiki/File:BMW_ Gina_Museum.jpg), BMW Gina Museum, "https:// creativecommons.org/licenses/by-sa/2.0/legalcode")

Figure 2 The Hiriko concept (see online version for colours)

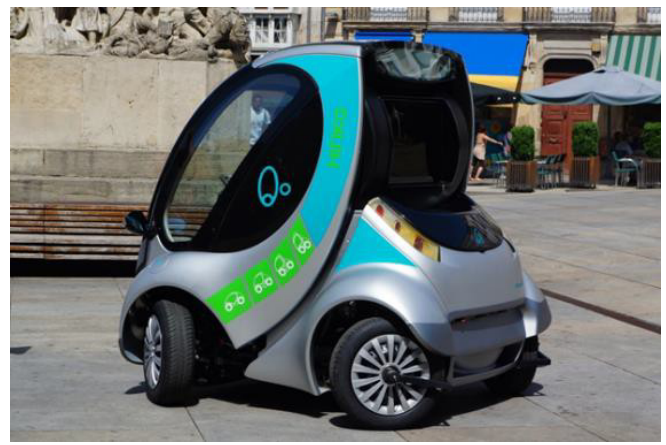

Courtesy: Robert Hextall ("https://commons.wikimedia.org/ wiki/File:Hiriko_1.jpg"), Hiriko 1, "https://creativecommons.org/ licenses/by/2.0/legalcode"

\section{Requirements of shape morphing structures}

Novel materials are required to achieve the goal of creating a morphing vehicle as traditional materials are incapable of delivering morphing (Donadon and Iannucci, 2014). The major requirements of a morphing structure are the ability to produce sufficiently high moments and forces for action and retain its shape in the presence of external forces while remaining lightweight (Elzey et al., 2003). Smart materials are considered as a good choice for morphing as they are capable of responding to stimuli. These have been widely studied and even implemented in aircraft structures. They deliver properties for self-sensing, self-assembly, self-adaptation, and self-healing.

Traditional approaches involved incorporating shape memory elements and piezoelectric elements into composite structures made of a flexible polymer matrix. Latest advances have centred on concepts like corrugated layer architecture and honeycomb providing relative densities as small as 2-3\% (Elzey et al., 2003). But some challenges need to be addressed in order to achieve the morphing form. The necessity of distributed high-power density actuation, flexible skins, and structural mechanisation are 
the key challenges in morphing aircraft design (Reich and Sanders, 2007). These are also the challenges in the design of a morphing vehicle. Efforts can be seen to focus on integrated active material principles that can use different kinds of stimuli to have applications in driving structural morphing, such as magnetic, electrical, chemical, and thermal. For deformation, it is observed that active materials or intelligent materials are bonded or incorporated into the structures. Figure 3 displays a schematic structure of the components of a morphing wing containing an actuation mechanism to directly actuate the flexible skin. Efforts were made in the study of morphing aircraft, and since the eighties, many programs such as the Project adaptive wing (Bonnema and Smith, 1993), the smart wing program (Kudva, 2004), the active aeroelastic wing program (Pendleton et al., 2013) and the morphing aircraft structure (Wlezien et al., 1998) have been carried out. Morphing has also been studied in underwater vehicles (Miller, 2009) which involved a system that consisted of a pliable hull wrapped around a standard pressure hull to increase the vehicle range by reducing drag. Studies have also been conducted using titanium alloys for wing applications (Fairuz et al., 2016), but they could not ensure good morphing performance.

Figure 3 Schematic structure of morphing wing (see online version for colours)

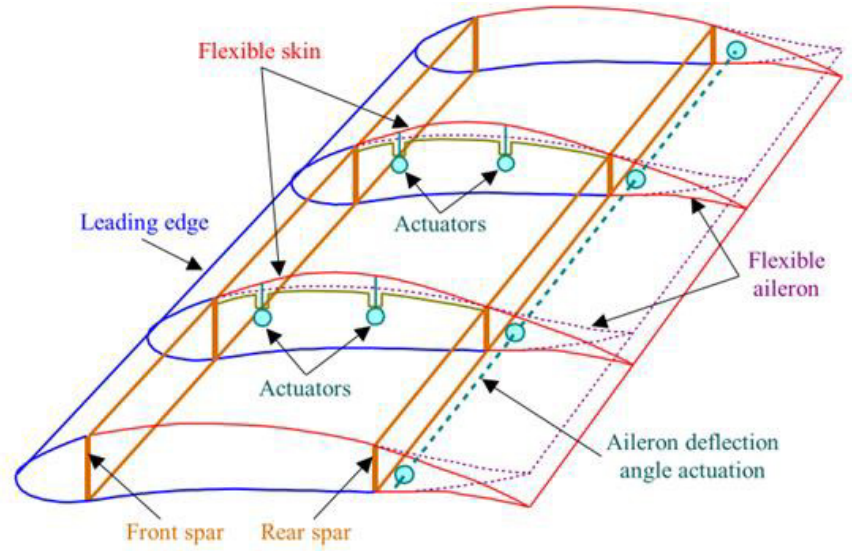

Source: Kammegne et al. $(2016,2017)$

\section{Smart materials}

Materials that detect and react to an external stimulus in a particular way are considered smart materials. They are also called active materials. They possess one or more physical properties that vary depending on the feedback given (Garcia, 2002). Because of their unique features and future relevance, smart materials have become increasingly relevant in the last few decades. Because of these materials, one component can perform functions that conventionally involve individual components for sensing, structure, and actuation (Garcia, 2002).

Shape memory polymers, shape memory alloys, electrorheological fluids, multifunctional nanocomposites, electroactive polymers, ferroelectric materials, magnetorheological fluids, magnetostrictive materials, piezoelectrical materials, and optical fibres are the most prominent smart materials currently available. There are also 
several smart materials applications. Thanks to their earlier availability, SMAs have possibly enjoyed the most widespread applications. SMAs have been widely used as actuators because they are lighter, more energy-efficient, and easily available. General Motors created a lightweight SMA wire to replace a heavy motorised hatch vent actuator to close and open a hatch vent which discharges air from the boot, which they announced for their 2014 Corvette (GM, 2013). Piezoelectric composites have found applications for noise and vibration reduction in helicopter rotors (Hall, 1990). At DLR, the German Aerospace Center, blades were integrated with piezoelectric composites for controlling blade twist rotor (Monner et al., 2011). Piezoelectric fans have been used in airflow generation for microelectronic cooling devices (Zubair et al., 2013), such as several LED source packages (Sufian et al., 2014). The smart material study has concentrated primarily on space applications, notably huge space structure pointing with precision and vibration control (Straub, 1996). In the past, morphing materials were used on UAVs (Gomez and Garcia, 2011), and few of those technologies could be implemented in a vehicle.

\section{Morphing actuation}

To reduce weight, complexity, and size, morphing applications favour embedded actuation. Actuation materials are either an active layer in a laminated composite (Bilgen et al., 2010), or incorporated in passive composite channels (Simoneau et al., 2014). Thermal loading can also be used to actuate passive composites (Eckstein et al., 2014). An ideal actuating material implanted in a morphing composite is expected to give better unit volume power output. The composite must also be able to operate in a range of frequencies suitable with the dynamics of the structure (Chillara et al., 2016). Piezoelectric materials are capable of generating adequate force but necessitate stroke intensification to attain larger deflection while retaining adequate frequency response and system rigidity (Huber et al., 1997). SMA can produce adequate stroke and force, but their usage is limited by their short limit of operating frequency. In the case of SMA, continuous shape regulation is one of the significant challenges. Hydraulic and pneumatic actuators are often used in the frequency range to produce large strokes and power, but certain weight penalties are included. Smart material-based miniature electrohydraulic actuators promise compact and lightweight solutions for fluid power harnessing (Chapman et al., 2005). They amplify short strokes of materials like magnetostrictive and piezoelectrics which have high-frequency bandwidth by fluid flow rectification. Morphing structures, bio-inspired structures, and soft robotic applications can make use of fluid-based actuation.

Pressurised artificial muscles and other linear actuators have been used in the development of robotic systems capable of folding and bending (Zhang and Philen, 2012). Flexible pneumatic bending actuators have been suggested for soft robotic hand capable of grasping objects (Deimel and Brock, 2013). Some advancements have been made in the field of biomimetics, such as an accommodating structure utilising fluid channels capable of mimicking a fish's motion (Marchese et al., 2014). Some researchers have created variable stiffness skins with embedded fluid muscles which have applications in morphing aircraft wings (Feng et al., 2015). These work by using fibre reinforcement to restrict radial expansion and by bonding linear actuator with a constraining layer to achieve bending. 
Piezoelectricity is the capability of some materials to produce an AC voltage when subjected to mechanical stress (Liu et al., 2009; Cho et al., 2005). A maximum strain of $0.1 \%$ is expected to develop on the application of a voltage to a piezoelectric material (Bogue, 2014). A major portion of the latest generation smart structures are piezoelectric actuators and sensors mounted in a sandwich and composite laminate to bring together self- sensing and actuating capabilities (Kapuria et al., 2010). PZT materials can strain by voltage application. They are usually delivered as thin patches but can be formed into large actuators by stacking. Increasing actuator output from $0.1 \%$ at present would be a technological improvement that would aid in the development of morphing structures. Several types of piezoelectric actuators have been designed and tested, including the 'O type', 'L-L type', and the ' $\mathrm{X}$ type'. Several studies have shown that piezoelectric composites are used to vary lift in aircraft, and the same idea can be applied to cars to increase downforce through the spoiler.

Shape memory alloy elements are used as solid-state actuators because of their unique mechanical characteristics such as high reversible strains around $10 \%$, high recoverable stress generation up to $800 \mathrm{MPa}$ (Tsoi et al., 2004). Multiple authors have demonstrated the use of thermomechanically trained SMA wires to function as linear actuators with shape memory effect (Baz et al., 2000; Song et al., 2000; Icardi, 2001; Sreekumar et al., 2009).

In the aerodynamic applications of morphing structures, SMA elements are appealing as they avoid the addition of flow-disturbing control elements. (Stanewsky, 2000). Several authors considered using SMAs for actuation purposes (Bil et al., 2013) because they save space, weight, and also reduce system complexity as a whole. Studies have concentrated on the utilisation of SMAs as linear actuators in reconfigurable airfoil applications (Strelec et al., 2003; Weisshaar, 2013) which allows an increase in the wing efficiency at different flow regimes in flight.

Figure 4 Conventional and smart material efficiency comparison (see online version for colours)

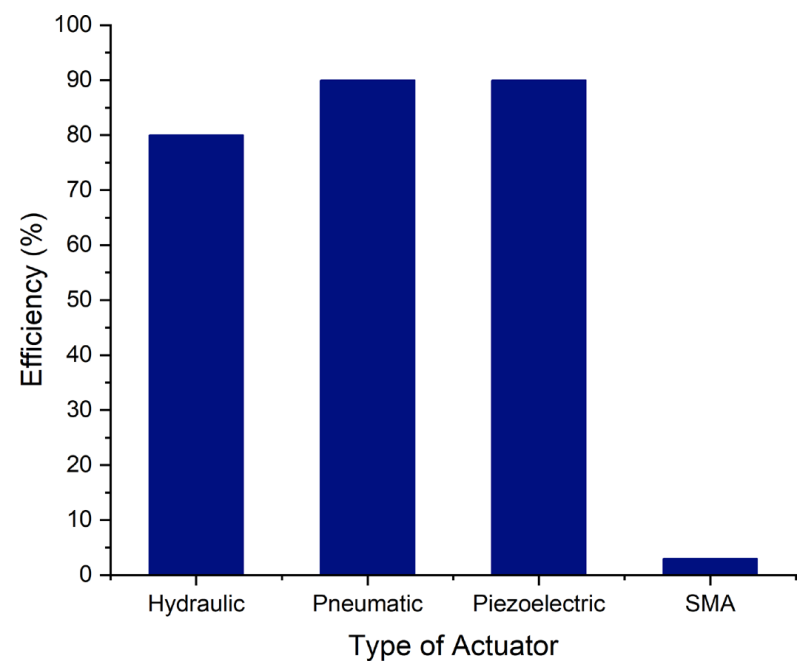

Source: Lederlé (2002)

Figures 4-6 show the comparison between the performance of a few traditional and smart materials. Shape memory alloys make for a good choice when the actuator has to provide 
substantial displacement and forces. These materials offer lower overall weights than hydraulic and pneumatic systems due to lack of pumps, fluid, etc. But their response time may not be as good as other materials. For actuation purposes, shape memory alloys can also generate large stress and strain.

Figure 5 Conventional and smart material strain comparison (see online version for colours)

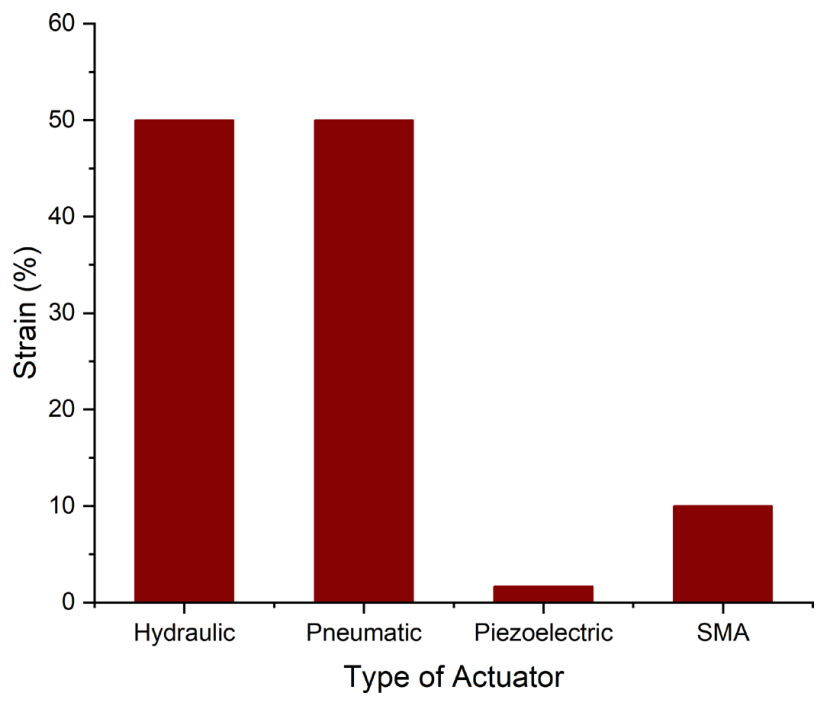

Source: Lederlé (2002)

Figure 6 Conventional and smart material stress comparison (see online version for colours)

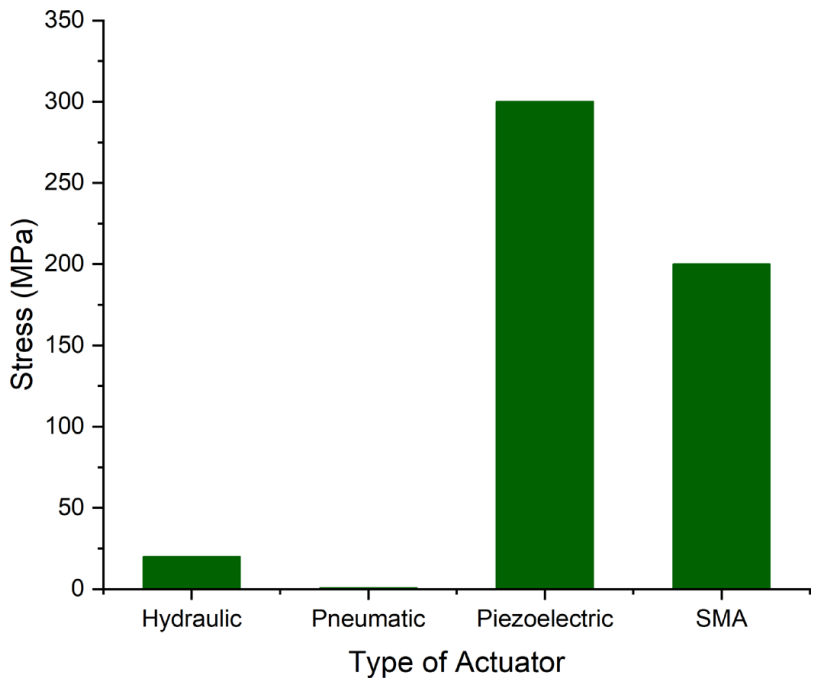

Source: Lederlé (2002)

In morphing blades development, embedded SMA strips have been proposed as actuators (Fortini et al., 2015). They used both 2D and 3D techniques to study the ability of SMAs to induce blade deformation. They also identified the shape setting treatment that permitted maximisation of the shape memory effect to produce maximum deflection of 
the blade structure. Electro-active polymers have also found application in trailing edge actuators of a fixed-wing UAV to boost lift (Molinari, 2016).

\section{Morphing skins}

The skin is of very high importance on a morphing structure; it enhances aerodynamic efficiency, enhances aesthetics, and protects the structures underneath. Conventional morphing studies concentrate on slight deformation in high-stiffness materials or massive deformation in non-structural materials with low stiffness. Morphing skins are expected to operate over a broad operating condition range. The primary challenge in developing morphing structures is to find a skin material and design that can bear aerodynamic loads and deform simultaneously. Improvements and innovations in this area would help humanity realise the ultimate goal of developing a shape morphing vehicle. While there are multiple studies of materials possessing potential morphing applications (Keihl, 2005; Thill et al., 2007; Barbarino et al., 2009; Rodriguez et al., 2016; Bai et al., 2017), commercially available versions of the same remain scarce.

Efforts can be seen focusing on integrated active material concepts that can have applications in structural morphing driving using different types of stimuli such as magnetic, electrical, chemical, and thermal stimuli (Leng et al., 2011). It is observed that active materials or smart materials are bonded or integrated into the materials to achieve deformation. Materials used as morphing skins should provide adequate resistance to chemical effects, environmental effects (UV radiation, heat), and abrasion resistance due to stones or any material on the road surface. It is usually believed that the morphing capabilities are substantially enhanced by using materials with variable stiffness. A survey of available morphing skin literature indicates shape memory polymers are a good choice for materials that involve significant deformation. Such polymers demonstrate the shape memory effect and may be utilised to achieve deformation when needed and to return to the original form later. However, several works suggest elastomers as a promising choice for morphing skins (Kudva, 2004; Yokozeki et al., 2006; Gandhi and Anusonti-Inthra, 2008). Certain studies have shown the development of many other materials that could be used as morphing skins. Kikuta (2003) experimentally tested and identified the best option among some commercially available shape memory polymers such as co-polyester elastomers, thermoplastic polyurethanes, and woven materials. Under DARPA/AFRL's morphing aircraft structure program, NextGen Aeronautics was successful in developing a wing that was able to modify its aspect ratio by $200 \%$, span by $40 \%$, and area by $70 \%$ (Gandhi and Anusonti-Inthra, 2008). A silicone skin with a high strain to failure ratio was made use of in the DARPA smart wing program (Kudva, 2004).

\subsection{Elastomers}

Elastomers are considered as one of the most suitable morphing skin choices. They offer the possibility of a seamless approach that includes very good compression and tension properties. They stiffen at low temperatures, and have low resistance to abrasion and fatigue due to high strain. With good strain capability, due to passive operation, they have low risk, elastic recovery using nominal strain values and an even aerodynamic surface provided by elastomers are useful in morphing skin applications (Murugan et al., 2011). 
Some examples for this include co-polyester elastomer, thermoplastic polyurethane, and woven elastane yarn materials among others.

Fibre-reinforced epoxy laminates that are conventionally used have 1-2\% tensile failure strain and around $0.5 \%$ transverse tensile failure strains (Zand et al., 2012). Elastomers are capable of undergoing strains higher than 25\% without failing (Murugan et al., 2011). Many previous ventures attempted to achieve larger morph areas, leading to expensive and heavy solutions (Schorsch et al., 2015). The SARITSU project supported by the European Union Seventh Framework explored an innovative approach to morphing by focusing on incorporating small polymer-based elements into the trailing edge and winglet (Iannuzzo et al., 2018). Schorsch et al. (2016) proposed a multi-material skin containing hard and soft sections where the hard sections provided the deformation compensation and the soft segments provided a smooth, gapless transition between the fixed and moving sections. Kikuta (2003) studied the mechanical properties of elastomeric materials that have morphing skin potential. Morphing skins such as shape memory polymers, co-polyester elastomer, thermoplastic polyurethane, etc. and suggested Tecoflex 80A as ideal for morphing skins. Gürdal et al. (2008) demonstrated that changeable stiffness concepts provide flexibility to the design for a tradeoff between buckling load and overall panel stiffness. Silicone rubber has been used as a raw material for flexible face sheets in sandwiched skins for providing improved aerodynamic properties and 9.2 change in sweep morphing angle and global strains of $98.6 \%$ for span morphing were achieved in simulations (Chen et al., 2015).

\subsection{Shape memory polymers}

'Shape memory polymers' are substances which demonstrate shape memory effect. These materials are extensively studied, and new advances are constantly emerging. A shape memory polymer foam sample for application in shape-morphing planes is shown in Figure 7. Polyurethane polymers are the most studied SMPs as they exhibit behaviour similar to Shape memory alloys. They are actuated through stimuli applied such as through electricity, heating, etc. Alternative stimuli to heat such as ultraviolet lights of dissimilar wavelength emfs and two-way SME are currently being widely investigated. Hence, shape memory polymers are considered suitable candidates for use as flexible skins (Perkins et al., 2004; Reed et al., 2005; Thill et al., 2008; Yu et al., 2009; He et al., 2018).

Shape memory polymers can be made to memorise shapes, so that when heat is applied a material will turn from Shape 1 to Shape 2 and Shape 3 (Bellin et al., 2006). Keihl et al. suggested that shape memory polymers are a promising alternative for morphing skins as the ability of SMPs to have several stable states enables them to effortlessly change shape by heating and cooling, allowing them to withstand significant loads (Keihl, 2005). Typical materials with high stiffness and piezoelectric actuators limit strain to less than $1 \%$, this makes it unsuitable for large deformation. Studies by McKnight et al indicated that designing a composite material that provides a high degree of change in modulus, reversibly accommodates the change in strains, and by changing the conditions in local geometry, the properties can be tailored (McKnight and Henry, 2005). Tupper et al. (Tupper et al., 2001) presented a similar idea, involving composite materials with elastic memory that are reinforced fibre composites containing a polymer resin which shows shape memory characteristics. SMP materials have certain limitations such as inaction to electromagnetic stimuli, poor thermal conductivity, and reduced 
strength as compared to shape memory alloys. Multiple approaches have been proposed to improve SMP properties, and shape memory polymer composites have been manufactured to resolve some of its constraints. To further improve the pure SMP properties, fillers or fibres were used to reinforce SMPC. Joule heating can bring SMP recovery by integrating carbon nanofibre, carbon nanotubes, graphene, ferromagnetic particles, and graphene into SMP resin. Graphene filled SMPCs have improved mechanical properties in comparison with carbon nano tube and carbon nano fibre fillers. The recovery process is triggered when electrical power is supplied to the SMP, the conductive fillers provide a resistance resulting in the SMP being heated as per Joule's law (Mat Yazik and Sultan, 2019). The incorporation of SMP as a skin material can lead to a reduction in the overall wing mass compared to traditional materials and therefore there is an increased need to develop SMP materials that can withstand higher aerodynamic loading, thus making it possible for SMPs to be used in full-scale aircraft requiring high-strength materials while allowing morphing in the soft state.

Figure 7 Shape memory polymer foam for shape-changing planes (see online version for colours)

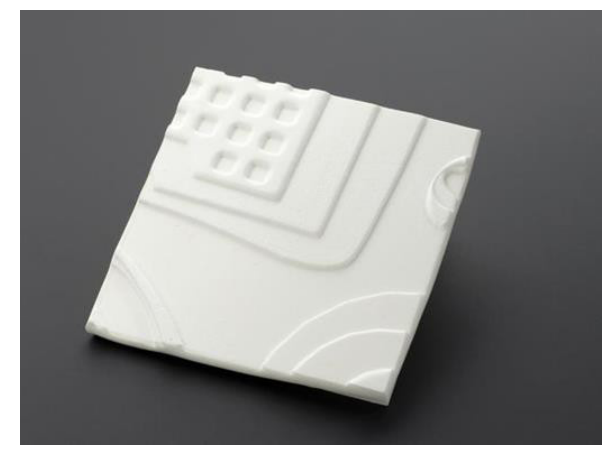

Courtesy: Science Museum London / Science and Society Picture Library (https://commons.wikimedia.org/wiki/File:One_sample_of_shapememory_polymer_foam,_as_researched_for_use_in_shapechanging_aeroplanes._(9672239254).jpg), „, Ōne sample of shapememory polymer foam, as researched for use in shape-changing aeroplanes. (9672239254)“, "https://creativecommons.org/ licenses/by-sa/2.0/legalcode"

Shape memory polymers also show a memory shape effect similar to shape alloys. Increasing the SMP temperature above the temperature of transition makes it soft and pliable by adding some load, as it cools down the polymers come back to their initial shape. This cycle, potentially, could be repeated indefinitely. Shape memory polymers can be extended up to $1100 \%$ and variation can be brought into their mechanical properties (Lendlein and Kelch, n.d.). They have potential applications from planes to household products in various sectors but not many have been introduced so far. Shapememory Polymers are still limited in availability. In addition to the traditional heat stimulus, stimuli like different wavelength UV lights, electromagnetic fields are also being investigated (Vincent, 2000). 


\subsection{Shape memory alloy}

The most popular and most studied smart materials are 'shape memory alloys'. They have the property of the shape memory effect that allows it to go back to its initial shape from the deformed shape upon heat application. While there are a range of alloys displaying SMEs, those that can recover significantly or produce the necessary amount of force on shifting shape are commercially of great interest.

Nickel-titanium and copper-based alloys such as $\mathrm{Cu}-\mathrm{Zn}-\mathrm{Al}$ and $\mathrm{Cu}-\mathrm{Al}-\mathrm{Ni}$ are the most widely studied (Van Humbeeck, 2001; Saadat et al., 2002; Eggeler et al., 2004). They are available in a variety of form factors such as wires, bars, and sheets. Their characteristics such as large recoverable strains, high output forces, controllability, and memory effects (one way and two way) make them suitable candidates for actuators. They can recover strains up to 8\% and stress upon heating (Dimitris_C_Lagoudas, 2007; Lagoudas, 2008).

A simple shape memory alloy definition would be one that yields thermoelastic martensite (Hodgson et al., 1990). The alloy undergoes a type of martensite transformation allowing the alloy to be distorted below the transformation temperature by a twinning mechanism. When the twinned structure returns to its original phase on heating, the deformation is reversed.

The start and end of the heating and cooling transformation extend over a wider temperature spectrum even though the bulk of the transformation happens within a fairly limited temperature range. The temperature-stress phase diagram for SMAs is shown in Figure 8. Historically shape memory transformation was recorded in 1932 by Chang and Read when they noticed the transformation reversibility in Au-Cd by resistivity changes and metallographic observations. Over the years, the study of shape memory alloys has gained traction and ushered several developments. Two paths have been utilised to develop their exclusive performance characteristics to expand their potential applications. The two methods include developing novel material and alloy systems and the development of hybrid materials combining the properties of conventional materials (Tsoi et al., 2004; Vokoun et al., 2016).

Figure 8 SMA temperature-stress phase diagram (see online version for colours)

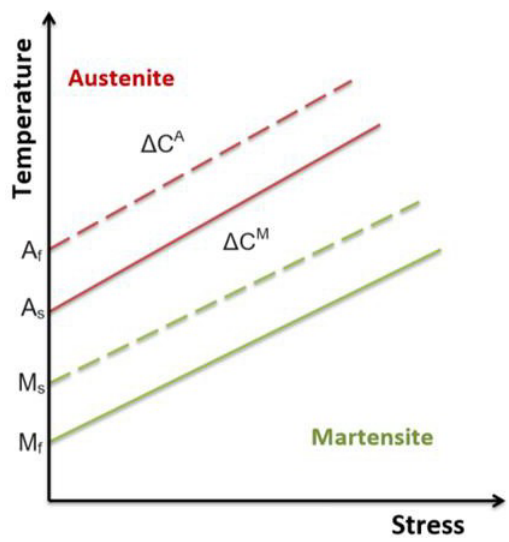

Most commercially available shape memory alloys are Ni-Ti alloys and copper-based alloys. They have different properties, Ni-Ti alloys have a higher shape memory strain of 
around $8 \%$ in comparison to $4-5 \%$ for copper based alloys, they are thermally stable, possess superior resistance to corrosion as compared to copper based alloys. But copper based alloys are cheaper and can easily melt and extrude in the air, and also have a wider range of temperatures for transformation (Hodgson et al., 1990). Usually, either of these two are chosen for morphing applications according to the requirements. Commercial copper based SMA is obtainable in ternary $\mathrm{Cu}-\mathrm{Al}-\mathrm{Ni}$ and $\mathrm{Cu}-\mathrm{Zn}-\mathrm{Al}$ alloys or their manganese-containing quaternary modifications. For grain refinement purposes elements such as titanium, iron, vanadium, boron, zirconium, and cobalt are also added.

Boeing used them as variable geometry chevrons in the airplane to decrease noise from take-off and improve cruise efficiency (Oehler et al., 2012), and other components. A soft morphing winglet by Han et al. (2016) allowing for multiple design elements such as height, tip-chord, and taper ratio to be controlled subject to the winglet geometry is shown in Figure 9. They were also used in the form of Ni-Ti wires (Kim et al., 1992) in blood clot filters and in other biomedical devices such as stents and implants. Table 1 provides a comparative analysis of significant characteristics of SMA and SMP. Both materials exhibit excellent corrosion resistance which proves to be a major advantage over conventional materials. The properties can be compared and selected based on the intended application.

Figure 9 Cross-sectional view of a soft morphing winglet (see online version for colours)

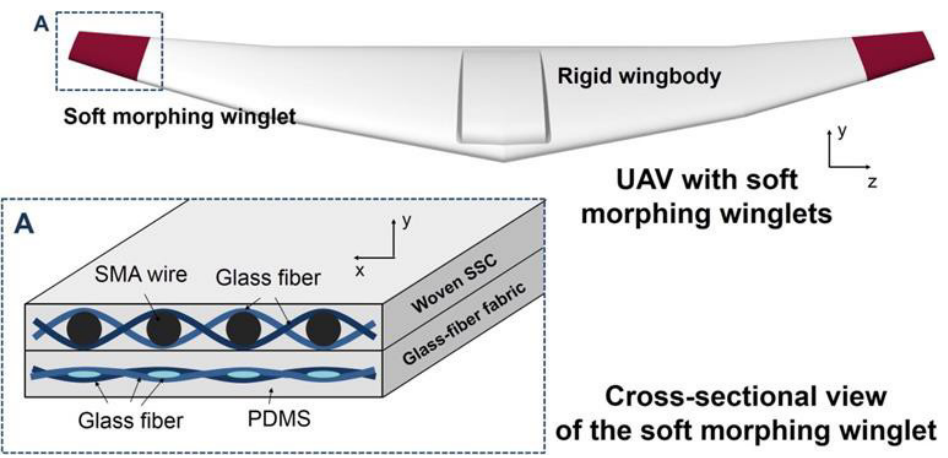

Courtesy: Min-Woo Han,Hugo Rodrigue,Hyung-Il Kim, Sung-Hyuk Song, Sung-Hoon Ahn (https://commons.wikimedia.org/ wiki/File:Winglet_sma.jpg), https://creativecommons.org/ licenses/by-sa/4.0/legalcode

Table 1 SMA and SMP property comparison

\begin{tabular}{|c|c|c|c|c|c|c|c|c|}
\hline Material & $\begin{array}{l}\text { Strain } \\
(\%)\end{array}$ & $\begin{array}{l}\text { Recovery } \\
\text { speed }\end{array}$ & $\begin{array}{l}\text { Corrosion } \\
\text { resistance }\end{array}$ & Density & $\begin{array}{c}\text { Deformation } \\
\text { stress }\end{array}$ & $\begin{array}{c}\text { Recovery } \\
\text { stress }\end{array}$ & Cost & $\begin{array}{l}\text { Shape } \\
\text { training }\end{array}$ \\
\hline $\begin{array}{l}\text { Shape } \\
\text { memory } \\
\text { alloy }\end{array}$ & $\leq 400$ & $\begin{array}{l}<1 \mathrm{~s} \text { to } \\
\text { several } \\
\text { mins }\end{array}$ & Excellent & $0.9-1.25$ & $1-3$ & $1-3$ & Low & $\begin{array}{l}\text { Fast and } \\
\text { easy }\end{array}$ \\
\hline $\begin{array}{l}\text { Shape } \\
\text { memory } \\
\text { polymer }\end{array}$ & $\leq 8$ & $<1 \mathrm{~s}$ & Excellent & $6-8$ & 50-200 & $150-300$ & High & Difficult \\
\hline
\end{tabular}

Source: Liu et al. (2007) and Ochoński (2010) 


\subsection{Corrugated composite and other morphing skin materials}

From a structural standpoint, there are differences between internal mechanisms comprising rigid parts with a flexible skin cover-based morphing solution (Monner, 2001; Amendola et al., 2016) and structures that are completely deformable (Campanile and Sachau, 2000; Airoldi et al., 2012). In both cases, the skin must endure the aerodynamic surface forces and transmit resultant forces to the underlying structures. Hence the ability to generate enormous recoverable strains without failing is one of the necessities of a morphing skin (Airoldi et al., 2017).

One of the researchers' promising solutions for morphing skins is corrugated composites. They can stretch and bend in the corrugated composite direction comfortably and display good rigidity and strength in the normal corrugation direction. An efficient skin system based on corrugated support with smooth aerodynamic profile elastomeric cover has been suggested by a few authors (Airoldi et al., 2017). In the direction of corrugation, corrugated sheets offer stiffening effects with improved compliance and failure strain. Because of the geometrical characteristics of corrugations, they are firm in the transverse direction and flexible along the direction of corrugation (Ghabezi and Golzar, 2013; Golzar and Ghabezi, 2014; Zhou et al., 2016; Thurnherr et al., 2017). Multiple corrugation types have been suggested for morphing such as rounded, trapezoidal, square, and circular. Round and trapezoidal shapes were some of the initial forms proposed for morphing applications (Yokozeki et al., 2006; Thill et al., 2007). A sinusoidal shape (Briassoulis, 1986; Aboura et al., 2004) normally used for corrugated cardboard, although considered for analytical studies by some authors was never implemented practically as a morphing skin solution. Circular shapes (Winkler and Kress, 2010; Kress and Winkler, 2011; Schmitz and Horst, 2014) making use of circular arcs with variable angular amplitudes are also possible morphing skins. Bai et al proposed a novel corrugated flexible composite skin that is built using twin thin-walled curved fibre-reinforced plastic composite shells that extend by pure elastic deformation for a long distortion process. This enables a considerable change in the FCS region for morphing applications (Bai et al., 2017). Philen et al. developed a skin of variable stiffness type with a flexible matrix and a flexible composite tube having pressurising fluid. By controlling the inlet pressure of the fluid the skin stiffness could be modified considerably (Shan et al., 2006; Philen et al., 2007). Murray et al proposed a high strain soft matrix embedded with a stiff fibre type of flexible matrix composite (FMC) skin (Murray et al., 2010). But some studies indicated that flexible silicone skins such as the one mentioned previously by Murray had low tear resistance and low load-bearing capacity (Kudva, 2004). The skin shape involving corrugates is optimised by decreasing weight and in-plane stiffness, and by its flexural out- of-plane stiffness (Ermakova and Dayyani, 2017).

As morphing skins, corrugated laminates pose certain inconveniences for adoption. They provide high bending stiffness in the non-morphing direction, which limits the need for skin support as it prevents bucking in that direction. Bending stiffness is low in the direction of morphing, leading to a risk of increased distortion under aerodynamic loads with unwanted aerodynamic surface flow results. Skin bubbling in the space in the middle of supports in the morphing direction was observed by Gandhi et al. (2008) and verified numerically in the reported morphing profile design (Airoldi et al., 2012). This was overcome by bonding the two corrugated laminates with a core made of foam (Thill et al., 2007, 2008). This indicates a distinctive kind of corrugation accomplished by 
combining two laminates that are simply corrugated. By selecting a proper corrugated laminate geometry and by fluctuating distances between the skin supports in the direction of morphing, insufficient bending stiffness effects in morphing directions could be solved. The avoidance of greater bending deformation in the morphing direction, taking into account the morphing internal structure, is a problem that should be addressed.

Chillara et al proposed a composite comprising a fluid layer, a limiting layer, and a mechanically pre-stressed layer that can be drawn into any required shape till a limiting flat shape by modulating the fluidic layer pressure (Chillara et al., 2016). Ramrakhyani et al. (2005) introduced an inner folder skin that, such as an elastomer, could provide lateral support to the flexible outer skin. With the load-bearing main substructure, this inner skin will be able to expand and contract. He also addresses the use of a multi-layered skin made up of many thin layers of conventional materials which are unbonded. This would not allow transverse shear stresses to be transmitted from one layer to another. Compared to a monoloth skin, this results in lower bending stiffness. Olympio and Gandhi (2010) was the first to suggest the concept of a flexible skin made of cellular honeycomb core with an accommodating face sheet cover, this is a potential morphing skin. The results of their work showed that the cellular cores were capable of withstanding strains ten times higher than the failure strain values of the normal aluminum/SMA core material. They also suggest that if the cores could be made-up of materials capable of high-strain, then higher global strains required for morphing applications may be possible.

Electro-active polymers are the materials that are electrically stimulated to generate a substantial shape change or size change. EAPs present advantages such as reduced weight, low energy consumption, quick response, and good flexibility. EAP materials include dielectric elastomers (DE), polyvinylidene fluoride (PVDF), and ionic polymermetal composites (IPMCs) among other such materials. Magnetostriction is the property by which certain materials undergo a dimension and shape change because of a magnetic field influence. A good example of a magnetostrictive substance is Terfenol-D (Moffett et al., 2005).

\section{Shape monitoring of morphing structures}

Shape monitoring is very important for a morphing structure to function safely and effectively. Traditionally, optic sensors were used to observe the health and shape of morphing structures (Wood et al., 2000), but this approach is still in its preliminary stages. Fibre-optic systems are rigid, high-priced, and unfit for large shape change monitoring as they are prone to failure. However, the system developed by Akl et al. (2007) did not suffer any of these drawbacks. The sensor network integration with the flexible actuator array and the supporting electronics will allow the creation of a new morphing class that is actively controlled, self-contained, and operated autonomously. The output is transmitted wirelessly to a control processor to calculate angular and linear deflections, the strain map distribution over the whole morphing surface and shape. The information on shape and deflection is necessary to ascertain the structure's deployment. 


\section{Automotive morphing}

The potential applications of morphing in a vehicle are numerous. They can be incorporated into most structures on the exterior panels, the interiors, and even some subsystem components. Some of these applications were exhibited by the GINA concept by BMW (Pagitz and Bold, 2013) and the Hiriko concept (Zhou et al., 2013).

While morphing can also be integrated into a road vehicle's interior, no major studies on its usability for such applications have been recorded. It is of great interest to build seats with shape-changing capabilities so that they enhance posture and increase comfort. Studies that can be carried out on enhancing a vehicle's overall aerodynamic profile by deliberately morphing body panels often provide an important opportunity for research. Morphing panels can be used for the reduction of turbulent flow as flow fields are generally turbulent in nature and the turbulence levels vary for different aerodynamic objects (Akula et al., 2012). Research and development outcomes from the aeronautical and aerospace sectors can be incorporated into the automobile sector too. It is also important to research the testing and validation of concepts and their performance in road vehicles.

\subsection{Aerodynamics}

It is well known that having a vehicle in any form of professional racing with the highest maximum speed does not guarantee performance. Racing is an art that is very dynamic and has different requirements.

Aerodynamic components are generally used in racing to generate a downforce resulting in a higher grip around corners (Katz, 2005) leading to faster lap times on high downforce circuits (Knight et al., 2018). Drag and lift requirements are very important to keep the vehicle planted on the track and providing better control. Spoilers (Figure 10) and diffusers (Figure 11) are the most commonly used devices to vary the drag and lift characteristics of a car. Spoilers are used to create downforce in a car. Implementation of morphing technology into the spoiler design and working aid to improved performance by tailoring the lift-to-drag ratio. A typical F1 car produces downforce that at $300 \mathrm{~km} / \mathrm{h}$ is nearly double its own weight. This is due to the general lift coefficient of -2 (Hucho, 1993). The capability to regulate this downforce by using passive or active methods by utilising morphing aerofoils resulted in a variation in the lift-to-drag ratio. The significant downforce generators are the front and rear wings and the diffuser, each contributing approximately one-third of the total downforce (Zhang et al., 2006). Without a good amount of downforce, the lateral acceleration that a vehicle can handle is very low (Iljaž et al., 2016). Currently, slat based multi-sectional wings, ailerons, and flaps adjust their camber and surface by the use of hinged parts that generate aerodynamic losses during morphing (Han et al., 2014). Self-actuated wings based on smart materials such as shape memory alloys and piezoelectric materials were developed resulting in a self-actuated wing devoid of mechanical subsystems (Barbarino et al., 2011; Thill et al., 2008).

This can be implemented in spoilers of race cars to achieve improved results. It is also possible to amplify aerodynamic effects to produce large increment forces by deforming the trailing edge without changing the angle of attack by using soft morphing mechanisms (Zhang et al., 2006). 
Figure 10 Rear spoiler of a 2008 Porsche 911997 Turbo (see online version for colours)

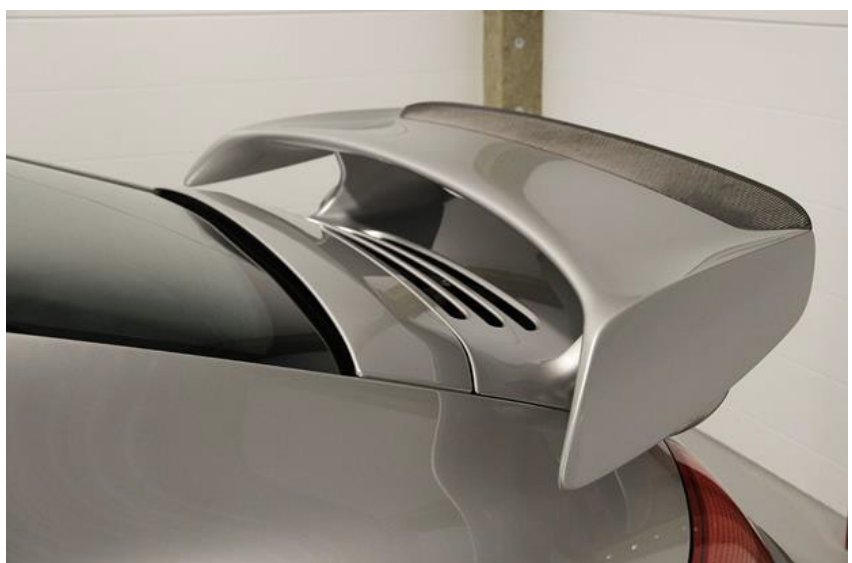

Courtesy: The Car Spy (“"https://commons.wikimedia.org/wiki/File:2008_ Porsche_911_997_Turbo_RUF_R T_12_-_Flickr_-

The Car_Spy.jpg"'), $200 \overline{8}$ Porsche $\overline{9} 11 \overline{9} \overline{9} 7$ Turbo RUF RT 12 $\overline{\text { Flickr }}$ - The Car Spy ("https://creativecommons.org/ licenses/by/2.0/legalcode")

Figure 11 Rear diffuser (see online version for colours)

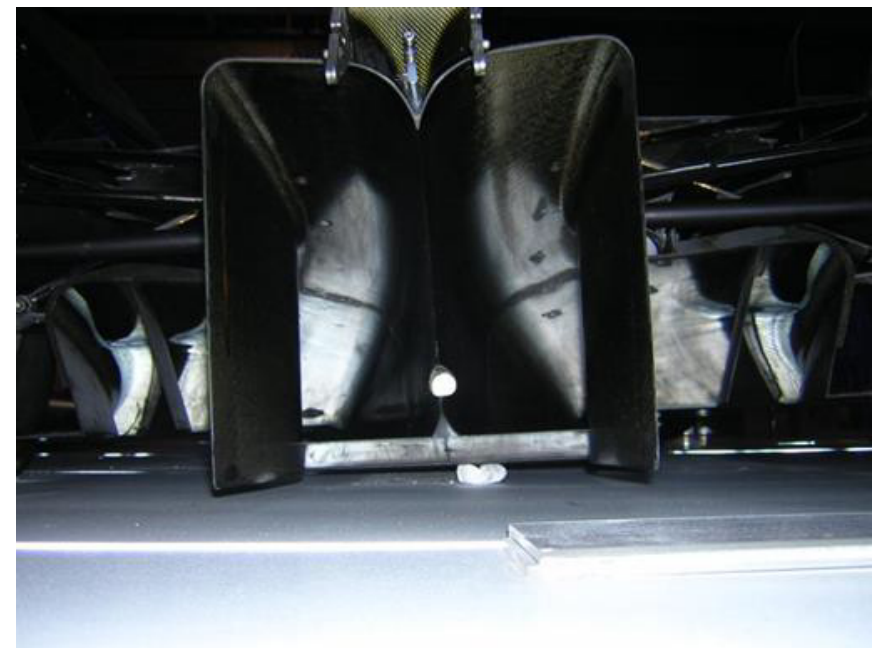

Courtesy: By gocarts - "https://www.flickr.com/photos/gocarts/3698924326/, CC BY 2.0", "https://commons.wikimedia.org/w/index.php? curid $=8954394 "$

Han et al. (2016) designed a shape-changing car spoiler using a reinforced elastomer made of woven SMA wires and glass fibres embedded in a soft polydimethylsiloxane matrix competent of sustained self-actuation completely along its surface and tested it on a small-scale vehicle. Testing was performed on the unconnected spoiler to confirm its aerodynamic effects utilising an open blow type wind tunnel. Outcomes have shown that the spoiler improved tyre adhesion by generating downforce and can morph on a track under different conditions, such as cornering and braking (Han et al., 2014). 
The shape of a vehicle's wings is believed to have a great impact on its aerodynamic properties (Rozhdestvensky, 2006). Smart material wings have continuous deformation ability without a discrete section and they also reduce system weight, complexity, and volume (Han et al., 2014). The CFD results obtained by Wordley et al expected that the wing would reach the target lift coefficient of 3.5 at an AoA of $31^{\circ}$. A gradual trailing edge separation on the rearmost flap was observed at higher AoA, with downforce steadily reducing and drag growing further than this angle (Wordley and Saunders, 2006).

Table 2 displays the various angles of attacks deemed optimum for performance by multiple-vehicle studies like formula SAE, BMW, and Audi models. The testing methods preferred by the authors are different. The studies show that having different AoA at different speeds generates the optimal downforce thus helping to keep the vehicle planted and stable. Hence having a morphing spoiler would help in achieving this requirement of different AoA at different speeds on the track.

Table 2 Optimal AoA comparison in different vehicles

\begin{tabular}{llllc}
\hline S. No. & Vehicle & Test method & Wing & Optimal angle \\
\hline 1 & $\begin{array}{l}\text { BMW E8 } \\
\text { (Buljac et al., 2016) }\end{array}$ & CFD & $\begin{array}{l}\text { Chord: } 150 \mathrm{~mm}, \\
\text { span: } 1800 \mathrm{~mm}\end{array}$ & $18^{\circ}$ \\
2 & $\begin{array}{l}\text { FSAE Car } \\
\text { (Kajiwara and Formula, }\end{array}$ & $\begin{array}{l}\text { CAE Analysis Wind Airfoil tools } \\
\text { tunnel test Driving } \\
\text { test }\end{array}$ & BE 50 original \\
& $\begin{array}{l}\text { 2017) } \\
\text { Model Audi R8 } \\
\text { (Thangadurai et al., 2018) }\end{array}$ & CAE analysis & NACA 2412 & $10^{\circ}$ at a low a high speed \\
4 & FSAE car & CFD & (Slat design), & $12^{\circ}$ \\
& (Iljaž et al., 2016) & & $\begin{array}{l}\text { 970 mm long } \\
\text { and 710 mm wide }\end{array}$ & $24^{\circ}$ \\
\hline
\end{tabular}

The field of adaptive structural morphing (ASM) aims to evolve, evaluate, and exhibit adaptive multifunctional wing systems that adjust to diverse conditions of flight efficiently and increase the controllability, flexibility, efficiency, and safety of upcoming aerospace vehicles (McGowan et al., 2002). The demonstration of a high-rate, morphcapable, hingeless wing, popularly known as the DARPA/AFRL/NASA Smart Wing was a highlight in the field of morphing in recent times. The results from these studies can be used as a stepping stone to the implementation of morphing in road vehicles including race cars. Doepke et al. (2015) investigated a high-performance actuation structure for active spoiler control with pressurised FMC actuators. An FMC active spoiler model was created using analysis tools using contracting and extensional actuators. Several actuator varieties were produced and tested in high pressure and loading to observe their competencies. Their prototype performed well under pseudo aerodynamic conditions.

Diffusers can also be incorporated with morphing technology to improve vehicle stability. They increase downforce and reduce drag hence significantly improving the aerodynamic efficiency of a high-speed car (Zhang et al., 2006). Diffusers are structures that create the venturi effect in which the variation in pressure causes the vehicle to be pulled towards the road and thus proves better grip and stability. Jason Knight et al studied long and short diffusers having a ratio of $35 \%$ and $10 \%$ respectively to that of vehicle length (Knight et al., 2018). Their results demonstrate that short diffusers 
generated poorer efficiency and peak downforce at lower ride height in comparison to the longer diffuser.

\subsection{Wheels}

Wheels are among the most important components of an automobile. For researchers, creative products such as morphing wheels have recently been of great interest. The primary objectives of these developments have been to boost the mobility of the vehicle. A deformable wheeled robot that was capable of changing the wheel shape depending on the obstacles (Koh et al., 2012) demonstrates the capabilities of such a concept. The concept demonstrated in their work employed smart structures and actuators such as deformable polymers, flexure linkages, and shape memory alloy actuators. It had different modes to overcome narrow gaps; drive fast and stair climbing capabilities. DARPA's reconfigurable wheel track (RWT) program (Mizokami, 2018) demonstrated a concept where round tyres transform into triangular tracks similar to ones found on tanks in seconds. The system was manufactured by National Robotics Engineering Center at Carnegie Mellon University. This system allows vehicles to conquer any terrain and improves manoeuvrability.

\subsection{Safety}

A boom in vehicle safety technologies and studies has been seen in recent years. Cars are becoming safer, but the risks posed to pedestrians remain. GHSA estimates that, in 2017, about 5984 pedestrians were killed in vehicle accidents around the world. Pedestrian deaths constitute a greater section of road accident deaths than in the last 33 years (Governors Highway Safety Association, 2018). Most pedestrian accidents occur during road-crossing and walking while around $12 \%$ of accidents happened while the pedestrian was standing in the road (Kumaresh et al., 2019).

Researchers across the globe have been trying to make vehicles safer not just for the passengers but also for the pedestrians in case of an accident. The body of conventional vehicles is always fixed, irrespective of its state. However, if the body could morph according to the situation the vehicle's safety could be improved. In this direction, a novel inflatable bumper concept named the 'I-bumper' was manufactured for improving the safety and crashworthiness of military and commercial vehicles (Lee et al., 2010). The system consisted of a number of active structural components such as a morphing mechanism, two explosive airbags, a movable bumper, and a morphing lattice structure having a locking mechanism. The inflated body will be capable of mitigating and splitting the crash energy. An active-release, stored energy concept that could be deployed in approx. $40 \mathrm{~ms}$ was exhibited by Radice et al. (2007). The system is resettable and could be tuned in the field for varying conditions. Another solution to enhancing pedestrian safety is the use of a bonnet lifting device that utilises shape memory alloys to impart the necessary speed and force of actuation (Strittmatter and Gü Mpel, 2011).

Morphing structures have a broad application range in automotive safety such as deployable protective cover on defense structures and vehicles that improve the crush distance on the identification of an impending impact. This reduces damage to the vital components of the vehicle. Lifting automotive hoods can also reduce fatalities and injuries during pedestrian accidents (Radice et al., 2007). Active solutions such as a launchable armour plating (Berning et al., 2002; Sterzelmeier et al., 2003) were 
demonstrated in the late 1990s but they were non-reusable Any such concepts require ultra-quick response speeds in the order of tens of milliseconds to be effective. Also, false deployment due to erroneous sensor data should be reduced. Reusability is a desired characteristic of such systems.

\subsection{Automotive interiors and seating}

Consumers expect their vehicles not only to facilitate travel from location A to location $\mathrm{B}$, but to do so in the greatest possible comfort. The interior of the vehicle has a significant impact on the comfort and satisfaction of the passenger. Morphing structure applications in automotive interiors and seating have seen an upward growth in recent years. Though the commercial availability of such systems is still limited, the field has gained the interest of researchers worldwide.

Grah et al. (2015) proposed form shifting vehicle seat backrests that allow the haptic sensing of obstacles in the rear periphery. Their prototype involved a $4 \times 4$ servomotor array that changed the backrest shape. This technology allows the driver to perceive approaching vehicles based on haptic stimuli. The haptic stimulus indicates the distance, speed, size, and position of an obstacle through seat changes. This avoids driver distraction and also helps improve safety. Continental introduced "Morphing Controls" where when the driver's hands approach a surface, three-dimensional buttons light up in place of smooth artificial leather and upon distancing his hands away, the buttons disappear once more (Continental, 2018). Entire morphing instrument panels have also been proposed. Such features not only improve the visual appeal but also enhance system ergonomics and utility. Similar instrumentation panels were displayed by Faurecia at CES-2019 where the display changes its position and the instrument panel surface smoothly adapts its shape based on the driving mode (Faurecia, 2019; Faurecia, 2018).

Seat assemblies based on shape memory polymers that control the seat shape and compliance for improved passenger comfort have been exhibited (Browne et al., 2007). One such invention that contributes to the morphing of automotive interior spaces is seat assemblies using active materials in operational contact with a seat surface designed to experience at least one property shift upon receipt of an active signal (Browne et al., 2007). Active materials have also been used in adjustable seat ramps (Lawall et al., 2009). Headrests impact passenger comfort highly and efforts have been made to incorporate active materials into the headrest assemblies to achieve shapeshifting (Browne et al., 2008).

\subsection{Body panels and styling}

A vehicle's exterior panels have defensive and decorative features. All while being aesthetically pleasing, it is important for the exterior panels to be clean, effective and secure. The human world has long been in fantasy of morphing exterior panels, structures, and materials. Several concepts that were seen as fantasy have started to take shape in the real world. In this work, numerous studies have already been discussed about morphing components and structures.

The creation of automotive body mouldings and surfaces that can morph on demand has been the aim of many companies and researchers. One such invention by General Motors is of a morphable member that utilises at least one active material to change an attribute in response to an activation signal (Browne et al., 2007). The attribute may be 
shape, dimension, contraction, expansion, or orientation. Such properties make this a desirable part of the modern automobile. Morphing structures capable of absorbing energy through an absorbent structure and an actuator within the energy-absorbing structure (Gandhi, 2017) help improve crash safety.

Active grilles have found their way into the market in recent times. Automotive manufacturers are always on the lookout for measures to reduce the carbon dioxide emissions of their vehicles. This requirement leads to a focus on smart air flap systems that permit improved cooling when open and decrease drag and time required to get the engine to operating temperatures. These panels provide several benefits such as improved heat retention and cold start, noise reduction, better cooling, etc. (Browne and Johnson, 2009). Several types of actuators are used for this purpose. Currently, electric actuators are being used (Pfeifer, 2014). The opening and termination of the grille are controlled by the system based on the driving cycle of the vehicle. Active grille shutter benefits on fuel economy were evaluated on the European homologation cycle (NEDC) at $-7^{\circ} \mathrm{C}$ and $+25^{\circ} \mathrm{C}$ and it was found to increase the fuel economy by $1.7-2.4 \%$ (Bouilly et al., 2015).

\section{Limitations and challenges}

In a discussion about smart materials for morphing application, consideration of the drawbacks and limitations of such materials is necessary. Most of the materials discussed in this review are expensive in comparison to conventionally used materials and mechanisms. This is one of the major reasons that automakers have not been interested in large scale implementation of morphing and the utilisation of smart materials. The cost of the materials might reduce over time as the technology matures and more suppliers can manufacture these materials.

Among shape memory alloys, the materials often have poor fatigue property, i.e., they do not survive as long as a steel component under similar loading conditions. Other issues include low energy efficiency, complex motion control, and thermo-mechanical behaviour, and low operation speed (Mehrpouya and Bidsorkhi, 2017). They also have high stiffness, comparatively inflexible transition temperature, recoverable strains of less than $8 \%$, and challenging processing conditions (Leng et al., 2011; Liu et al., 2007).

A major issue with shape memory polymer is with their low recovery stress (less than or equal to $10 \mathrm{MPa}$ ), low recovery speed, and lower achievable life cycle as compared to SMA's (Wei et al., 1998; Rousseau, 2008; Lu et al., 2010). Electrostrictive materials have higher strain capabilities as compared to piezoelectric materials but drop a major percentage of this strain if not used within a narrow temperature spectrum. Magnetostrictive materials change length in response to the magnetic field. For generating this field, magnets are necessary, and thus an inherent disadvantage with them is that they add weight and volume to a system (Straub, 1996). Piezoelectric actuators are not suitable for large bending on account of their low strain of $0.1 \%$ (Kim et al., 2010).

\section{Summary}

Morphing structures are of significant interest to researchers across the globe. Over the past few decades, there have been numerous studies and experiments of these systems in aerospace and aeronautical applications but studies in the field of automobiles have been 
limited and there are very few commercial incorporations of this technology. The popular actuation methods and types of skin materials, that include shape memory alloys, shape memory polymers, and elastomers, were discussed in this review. The application in automobiles of morphing technology has been described.

Multiple authors have proposed shape memory polymers, shape memory alloys, and elastomers as suitable skins for morphing applications. Additionally, other materials are being studied, such as corrugated skins and flexible skins, as they have possible morphing applications. Corrugated skins provide the right balance of strength and flexibility required for morphing. Shape memory materials such as SMAs and SMPs have been widely studied for use in morphing applications and some commercially available materials can be used for morphing studies. Actuators are necessary for the timely and correct actuation of these systems. There are many types of actuation methods available such as Ultraviolet lights, electromagnetic field, and thermal actuation. Some of the commonly used ones have been briefly addressed. SMA and piezoelectric actuators have some of the required properties for morphing and depending on the application they could be selected based on the comparison. Sensors are necessary for the identification and monitoring of morphing; these offer interesting research options.

There are a number of morphing applications in a car, and this provides various topics of research. This work briefs on applications of aerodynamics, wheels, safety, interiors, seating, body panels, and styling. Several studies have shown that the different angle of attack of the rear spoiler is important for the vehicle to function optimally and that morphing structures provide the ideal solution to this requirement. In terms of aesthetics, morphing systems can not only make an automobile better, but also improve the safety, utility, and performance of different components. Several studies and developments in the field of automotive morphing have been performed, but there is minimal commercial availability.

\section{Future scope}

Smart materials are one of the best choices for morphing skins and structures thanks to their properties, although there are many other materials commercially available and studies have been carried out on some of them. However, there are few commercial applications of such materials. SMAs and SMPs are widely-used when there is a need for change in size as they can be brought back to their initial shape and size upon heat application. Piezoelectric materials are also used as smart materials. There are other materials such as elastomers etc. that can be used as morphing skins, studies are being performed in the field. Many concepts demonstrated potential performance, operational, and aerodynamic advantages in comparison to current technologies.

Studies on the identification of alternative materials for use in morphing applications should be carried out, including eco-friendly materials, as the industry adapts to green methods wherever possible. This can also result in morphing being effective and efficient. Flexible materials exhibiting SME can be used as an external skin, for intake and ventilation ducts, in spoilers for downforce variation among others. Studies should also concentrate on the development of morphing structures in the interiors of a vehicle. Embedding devices in laminated structures can also help in achieving morphing. An interesting area for researchers would be smart material-based structures obtained through $3 \mathrm{D}$ printing. 
Morphing structures would greatly benefit the interior components such as seats and doors, as they would have better aesthetics while also improving performance. There is a desirable commercial availability of such components and systems.

Morphing structures may have been a topic of fiction in the past but studies and advancements in this field have made it a reality and further development of such ideas will produce a new generation of automobiles that will take the industry down a new, exciting path.

\section{References}

Aboura, Z., Talbi, N., Allaoui, S. and Benzeggagh, M.L. (2004) 'Elastic behavior of corrugated cardboard: experiments and modeling', Composite Structures, Vol. 63, No. 1, pp.53-62, doi: 10.1016/S0263-8223(03)00131-4.

Airoldi, A., Crespi, M., Quaranti, G. and Sala, G. (2012) 'Design of a morphing airfoil with composite chiral structure', Journal of Aircraft, Vol. 49, No. 4, pp.1008-1019, doi: 10.2514/1.C031486.

Airoldi, A., Fournier, S., Borlandelli, E., Bettini, P. and Sala, G. (2017) 'Design and manufacturing of skins based on composite corrugated laminates for morphing aerodynamic surfaces', Smart Materials and Structures, IOP Publishing, Vol. 26, No. 4, doi: 10.1088/1361-665X/aa6069.

Akl, W., Poh, S. and Baz, A. (2007) 'Wireless and distributed sensing of the shape of morphing structures', Sensors and Actuators, A: Physical, Vol. 140, No. 1, pp.94-102, doi: 10.1016/j. sna.2007.06.026.

Akula, P.K., Singh, B., Manikandan, M. and Srinivas, G. (2012) 'Influence of tip clearance on the turbulent aerodynamics of axial flow fan under off design conditions', Applied Mechanics and Materials, Vol. 232, pp.223-227, doi: 10.4028/www.scientific.net/amm.232.223

Amendola, G., Dimino, I., Magnifico, M. and Pecora, R. (2016) 'Distributed actuation concepts for a morphing aileron device', Aeronautical Journal, Vol. 120, No. 1231, pp.1365-1385, doi: 10.1017/aer.2016.64.

Bai, J.B., Chen, D., Xiong, J.J. and Shenoi, R.A. (2017) 'A corrugated flexible composite skin for morphing applications', Composites Part B: Engineering, Elsevier Ltd, Vol. 131, pp.134-143, doi: 10.1016/j. compositesb.2017.07.056.

Barbarino, S., Bilgen, O., Ajaj, R.M., Friswell, M.I. and Inman, D.J. (2011) 'A review of morphing aircraft', Journal of Intelligent Material Systems and Structures, Vol. 22, No. 9, pp.823-877, doi: $10.1177 / 1045389 X 11414084$.

Barbarino, S., Pecora, R., Lecce, L., Concilio, A., Ameduri, S. and Calvi, E. (2009) 'A novel SMAbased concept for airfoil structural morphing', Journal of Materials Engineering and Performance, Vol. 18, Nos. 5-6, pp.696-705, doi: 10.1007/s11665-009-9356-3.

Baz, A., Chen, T. and Ro, J. (2000) 'Shape control of NITINOL-reinforced composite beams', Composites Part B: Engineering, Vol. 31, No. 8, pp.631-642, doi: 10.1016/S13598368(00)00034-2.

Bellin, I., Kelch, S., Langer, R. and Lendlein, A. (2006) 'Polymeric triple-shape materials', Proceedings of the National Academy of Sciences, Vol. 103, No. 48, pp.18043-18047, doi: 10.1073/pnas.0608586103.

Berning, P.R., Hummer, C.R. and Hollandsworth, C.E. (2002) 'A coilgun-based plate launch system', IEEE Transactions on Magnetics, Vol. 35, No. 1, pp.136-141, doi: 10.1109/ 20.738391 .

Bil, C., Massey, K. and Abdullah, E.J. (2013) 'Wing morphing control with shape memory alloy actuators', Journal of Intelligent Material Systems and Structures, Vol. 24, No. 7, pp.879-898, doi: $10.1177 / 1045389 \times 12471866$. 
Bilgen, O., Kochersberger, K.B., Inman, D.J. and Ohanian, O.J. (2010) 'Novel, bidirectional, variable-camber airfoil via macro-fiber composite actuators', Journal of Aircraft, Vol. 47, No. 1, pp.303-314, doi: 10.2514/1.45452.

Bogue, R. (2014) 'Smart materials: a review of capabilities and applications', Assembly Automation, Vol. 34, No. 1, pp.16-22, doi: 10.1108/AA-10-2013-094.

Bonnema, L.K. and Smith, B.S. (1993) AFTI/ F-111 Mission Adaptive Wing, pp.69-77.

Bouilly, J., Lafossas, F., Mohammadi, A. and Van Wissen, R. (2015) 'Evaluation of fuel economy potential of an active grille shutter by the means of model based development including vehicle heat management', SAE International Journal of Engines, Vol. 8, No. 5, pp.2394-2401, doi: 10.4271/2015-24-2536.

Briassoulis, D. (1986) 'Equivalent orthotropic properties of corrugated sheets', Computers and Structures, Vol. 23, No. 2, pp.129-138, doi: 10.1016/0045-7949(86)90207-5.

Browne, A. and Johnson, N. (2009) Reversibly Opening and Closing a Grille using Active Materials.

Browne, A., Chernoff, A., Glaser, R., Johnson, N., Khoury, J., Ukpai, U. and Zavattieri, P. (2008) Active Material Actuated Headrest Assemblies, doi: 10.1038/incomms1464.

Browne, A., Johnson, N., Zavattieri, P., Ukpai, U., Ulicny, J., Cafeo, J., Glaser, R., Jones, G., Khoury, J., Perelli, C.A., Rodgers, W. and Gao, X. (2007) Active Material based Conformable and Reconfigurable Seats.

Browne, A., Pointe, G. and Johnson, N. (2007) Shape Memory Polymer Seat Assembles.

Buljac, A., Džijan, I., Korade, I., Krizmanić, S. and Kozmar, H. (2016) 'Automobile aerodynamics influenced by airfoil-shaped rear wing', International Journal of Automotive Technology, Vol. 17, No. 3, pp.377-385, doi: 10.1007/s12239-016-0039-4.

Campanile, L.F. and Sachau, D. (2000) 'Belt-rib concept: a structronic approach to variable camber', Journal of Intelligent Material Systems and Structures, Vol. 11, No. 3, pp.215-224, doi: 10.1106/6H4B-HBW3-VDJ8-NB8A.

Chapman, E.G., Herdic, S.L., Keller, C.A. and Lynch, C.S. (2005) Development of Miniaturized Piezo-Hydraulic Pumps, Vol. 5762, pp.299-310, doi: 10.1117/12.605967.

Chen, J., Shen, X. and Li, J. (2015) 'Zero Poisson's ratio flexible skin for potential twodimensional wing morphing', Aerospace Science and Technology, Elsevier Masson, SAS, Vol. 45, pp.228-241, doi: 10.1016/j. ast.2015.05.011.

Chillara, V.S.C., Headings, L.M. and Dapino, M.J. (2016) 'Multifunctional composites with intrinsic pressure actuation and prestress for morphing structures', Composite Structures, Elsevier Ltd., Vol. 157, pp.265-274, doi: 10.1016/j. compstruct.2016.08.044.

Cho, J.W., Kim, J.W., Jung, Y.C. and Goo, N.S. (2005) 'Electroactive shape-memory polyurethane composites incorporating carbon nanotubes', Macromolecular Rapid Communications, Vol. 26, No. 5, pp.412-416, doi: 10.1002/marc.200400492.

Chopra, I. (2002) 'Review of state of art of smart structures and integrated systems', AIAA Journal, Vol. 40, No. 11, pp.2145-2187, doi: 10.2514/2.1561.

Continental (2018) Buttons from Nothing: Continental Exhibits Functional Surfaces for the Driver's Cab of the Future. Available at: https://www.continental.com/en/press/pressreleases/morphing-controls-132066

Daynes, S. and Weaver, P.M. (2013) 'Review of shape-morphing automobile structures: concepts and outlook', Proceedings of the Institution of Mechanical Engineers, Part D: Journal of Automobile Engineering, Vol. 227, No. 11, pp.1603-1622, doi: 10.1177/0954407013496557.

Deimel, R. and Brock, O. (2013) 'A compliant hand based on a novel pneumatic actuator', Proceedings - IEEE International Conference on Robotics and Automation, pp.2047-2053, doi: 10.1109/ICRA.2013.6630851.

Dimitris_C_Lagodas (2007) [Dimitris_C_Lagoudas (2007)]_Shape_memory_alloys modeling.pdf 
Doepke, E.B. and Philen, M. (2015) 'Design and testing of a FMC actuated morphing Aileron', 23rd AIAA/AHS Adaptive Structures Conference. Reston, American Institute of Aeronautics and Astronautics, Virginia, pp.1-14, doi: 10.2514/6.2015-1259.

Donadon, M.V. and Iannucci, L. (2014) 'A numerical study on smart material selection for flapped and twisted morphing wing configurations', Journal of Aerospace Technology and Management, Vol. 6, No. 3, pp.281-290, doi: 10.5028/jatm.v6i3.341.

Eckstein, E., Pirrera, A. and Weaver, P.M. (2014) 'Multi-mode morphing using initially curved composite plates', Composite Structures, Vol. 109, No. 1, pp.240-245, doi: 10.1016/j. compstruct.2013.11.005.

Eggeler, G., Hornbogen, E., Yawny, A., Heckmann, A. and Wagner, M. (2004) 'Structural and functional fatigue of NiTi shape memory alloys', Materials Science and Engineering A, Vol. 378, Nos. 1-2, SPEC. ISS., pp.24-33, doi: 10.1016/j.msea.2003.10.327.

Elzey, D.M., Sofla, A.Y.N. and Wadley, H.N.G. (2003) 'A bio-inspired high-authority actuator for shape morphing structures', in Lagoudas, D.C. (Ed.): Proceedings Volume 5053, Smart Structures and Materials 2003: Active Materials: Behavior and Mechanics, p.92, doi: $10.1117 / 12.484745$.

Ermakova, A. and Dayyani, I. (2017) 'Shape optimisation of composite corrugated morphing skins', Composites Part B: Engineering, Elsevier Ltd, Vol. 115, pp.87-101, doi: 10.1016/j. compositesb.2016.10.029.

Fairuz, Z.M., Abdullah, M.Z., Zubair, M., Abdul Mujeebu, M., Abdullah, M.K., Yusoff, H. and Abdul Aziz, M.S. (2016) 'Effect of wing deformation on the aerodynamic performance of flapping wings: fluid-structure interaction approach', Journal of Aerospace Engineering, Vol. 29, No. 4, p.04016006, doi: 10.1061/(ASCE)AS.1943-(5525)0000548.

Faurecia (2018) Faurecia Displays its 'Cockpit of the Future' in India, Available at: $\mathrm{https}$ ://www.autocarpro.in/news-national/faurecia-displays-cockpit-future-india-29920 (Accessed 3 May, 2019).

Faurecia (2019) FAURECIA_CES2019, Available at. http://faurecia-ces.com/?wid=2fdad1f81 a531a77001043

Feng, N., Liu, L., Liu, Y. and Leng, J. (2015) 'A bio-inspired, active morphing skin for camber morphing structures', Smart Materials and Structures, Vol. 24, No. 3, doi: 10.1088/09641726/24/3/035023.

Fortini, A., Suman, A., Merlin, M. and Garagnani, G.L. (2015) 'Morphing blades with embedded SMA strips: an experimental investigation', Materials and Design, Elsevier, B.V., Vol. 85, pp.785-795, doi: 10.1016/j. matdes.2015.07.175.

Gandhi, F. and Anusonti-Inthra, P. (2008) 'Skin design studies for variable camber morphing airfoils', Smart Materials and Structures, Vol. 17, No. 1, doi: 10.1088/0964-1726/17/ $01 / 015025$.

Gandhi, U. (2017) Morphing Energy Absorber System for a Vehicle Assembly.

Garcia, E. (2002) 'Smart structures and actuators: past, present, and future', in McGowan, A-M.R. (Ed.): Proc. SPIE 4698, Smart Structures and Materials 2002: Industrial and Commercial Applications of Smart Structures Technologies, San Diego, California, USA, pp.1-12, doi: 10.1117/12.475054.

Ghabezi, P. and Golzar, M. (2013) 'Mechanical analysis of trapezoidal corrugated composite skins', Applied Composite Materials, Vol. 20, No. 4, pp.341-353, doi: 10.1007/s10443-0129267-6.

GM (2013) Corporate Newsroom United States Chevrolet Debuts Lightweight 'Smart Material' on Corvette, Available at: https://media.gm.com/media/us/en/gm/home.detail.html/content/ Pages/news/us/en/2013/Feb/0212-corvette.html\#: :text=DETROIT - From its fiberglass body, its predecessor $\% 2 \mathrm{C}$ that trend continues

Golzar, M. and Ghabezi, P. (2014) 'Corrugated composite skins', Mechanics of Composite Materials, Vol. 50, No. 2, pp.137-148, doi: 10.1007/s11029-014-9401-7. 
Gomez, J.C. and Garcia, E. (2011) 'Morphing unmanned aerial vehicles', Smart Materials and Structures, Vol. 20, No. 10, doi: 10.1088/0964-1726/20/10/103001.

Governors Highway Safety Association (2018) Spotlight on Highway Safety: Pedestrian Traffic Fatalities by State, Available at: https://www.ghsa.org/sites/default/files/2018-03/pedes trians_18.pdf

Grah, T., Epp, F., Wuchse, M., Meschtscherjakov, A., Gabler, F., Steinmetz, A. and Tscheligi, M. (2015) 'Dorsal haptic display: a shape-changing car seat for sensory augmentation of rear obstacles', Proceedings of the 7th International Conference on Automotive User Interfaces and Interactive Vehicular Applications, ACM, New York, NY, USA, pp.305-312, doi: $10.1145 / 2799250.2799281$.

Gürdal, Z., Tatting, B.F. and Wu, C.K. (2008) 'Variable stiffness composite panels: effects of stiffness variation on the in-plane and buckling response', Composites Part A: Applied Science and Manufacturing, Vol. 39, No. 5, pp.911-922, doi: 10.1016/j. compositesa.2007.11.015.

Hall, S. (1990) 'Piezoelectric actuators for helicopter rotor control', 31st Structures, Structural Dynamics and Materials Conference, American Institute of Aeronautics and Astronautics, Reston, Virigina, doi: 10.2514/6.1990-1076.

Han, M., Rodrigue, H., Cho, S., Song, S., Wang, W., Chu, W. and Ahn, S. (2016) 'Woven type smart soft composite for soft morphing car spoiler', Composites Part B, Elsevier Ltd, Vol. 86, pp.285-298, doi: 10.1016/j. compositesb.2015.10.009.

Han, M., Rodrigue, H., Cho, S., Song, S-H., Chu, W-S., Choi, H. and Ahn, S-H. (2014) 'Design and performance evaluation of soft morphing car-spoiler', Volume 5A: 38th Mechanisms and Robotics Conference, p.V05AT08A037, doi: 10.1115/DETC2014-34915.

Han, M.W., Rodrigue, H., Kim, H.I., Song, S.H. and Ahn, S.H. (2016) 'Shape memory alloy/glass fiber woven composite for soft morphing winglets of unmanned aerial vehicles', Composite Structures, Elsevier Ltd, Vol. 140, pp.202-212, doi: 10.1016/j.compstruct.2015.12.051.

He, D., Xie, Y., Wang, X. and Zhang, Z. (2018) 'Significantly enhanced electromechanical performance of PDMS crosslinked PVDF hybrids', Polymers, Vol. 10, No. 7, p.714, doi: 10.3390/polym10070714.

Hodgson, D., Wu, M.H. and Robert, B. (1990) 'Shape memory alloys', Properties and Selection: Nonferrous Alloys and Special-Purpose Materials, Elsevier, pp.897-902, doi: 10.1016/B978008044019-4/50031-3.

Huber, J.E., Fleck, N.A. and Ashby, M.F. (1997) 'The selection of mechanical actuators based on performance indices', Proceedings of the Royal Society A: Mathematical, Physical and Engineering Sciences, Vol. 453, No. 1965, pp.2185-2205, doi: 10.1098/rspa.1997.0117.

Hucho, I. (1993) 'Aerodynamics of road vehicles', Annual Review of Fluid Mechanics, Vol. 25, No. 1, pp.485-537, doi: 10.1146/annurev.fluid.25.1.485.

Iannuzzo, G., Russo, S., Apicella, A., Rossi, L. and Esposito, S. (2018) Morphing Wing Integration, Morphing Wing Technologies: Large Commercial Aircraft and Civil Helicopters, Elsevier Ltd, doi: 10.1016/B978-0-08-100964-2.00020-4.

Icardi, U. (2001) 'Large bending actuator made with SMA contractile wires: theory, numerical simulation and experiments', Composites Part B: Engineering, Vol. 32, No. 3, pp.259-267, doi: 10.1016/S1359-8368(00)00062-7.

Iljaž, J., Škerget, L., Štrakl, M. and Marn, J. (2016) 'Optimization of SAE formula rear wing', Strojniski Vestnik/Journal of Mechanical Engineering, Vol. 62, No. 5, pp.263-272, doi: 10.5545/sv-jme.2016.3240.

Kajiwara, S. and Formula, Á. (2017) 'Passive variable rear-wing aerodynamics of an open-wheel racing', Automotive and Engine Technology, Springer International Publishing, Vol. 2, No. 1, pp.107-117, doi: 10.1007/s41104-017-0021-9.

Kammegne, M.J.T., Botez, R.M. and Grigorie, T.L. (2016) 'Actuation mechanism control in a morphing application with a full-scaled portion of an aircraft wing', Proceedings of the IASTED International Conference on Modelling, Identification and Control, Vol. 830, February, pp.122-129, doi: 10.2316/P.2016.830-031. 
Kammegne, M.J.T., Botez, R.M., Grigorie, L.T., Mamou, M. and Mébarki, Y. (2017) 'Proportional fuzzy feed-forward architecture control validation by wind tunnel tests of a morphing wing', Chinese Journal of Aeronautics, Vol. 30, No. 2, pp.561-576, doi: 10.1016/j. cja.2017.02.001.

Kapuria, S., Kumari, P. and Nath, J.K. (2010) 'Efficient modeling of smart piezoelectric composite laminates: a review', Acta Mechanica, Vol. 214, Nos. 1-2, pp.31-48, doi: 10.1007/s00707010-0310-0.

Katz, J. (2005) 'Aerodynamics of race cars', Annual Review of Fluid Mechanics, Vol. 38, No. 1, pp.27-63, doi: 10.1146/annurev.fluid.38.050304.092016.

Keihl, M.M. (2005) 'Mechanical properties of shape memory polymers for morphing aircraft applications', Proceedings of SPIE No. 57,2pp.) 143-151, doi: 10.1117/12.600569.

Kikuta, M.T. (2003) Mechanical Properties of Candidate Materials For Morphing Wings, Virginia Polytechnic Institute and State University, p.138.

Kim, D., Edelman, R.R., Margolin, C.J., Porter, D.H., McArdle, C.R., Schlam, B.W., Gianturco, L.E., Siegel, J.B. and Simon, M. (1992) 'The simon nitinol filter: evaluation by MR and ultrasound', Angiology, Vol. 43, No. 7, pp.541-548, doi: 10.1177/ 000331979204300701.

Kim, H.A., Betts, D.N., Salo, A.I.T. and Bowen, C.R. (2010) 'Shape memory alloy-piezoelectric active structures for reversible actuation of bistable composites', AIAA Journal, Vol. 48, No. 6, p.1265-1268, doi: 10.2514/1.J050100.

Knight, J., Spicak, M., Kuzenko, A., Haritos, G. and Ren, G. (2018) 'Investigation of vehicle ride height and diffuser ramp angle on downforce and efficiency', Proceedings of the Institution of Mechanical Engineers, Part D: Journal of Automobile Engineering, p.095440701877676, doi: 10.1177/0954407018776767.

Koh, J., Lee, D., Kim, S. and Cho, K. (2012) 'Deformable soft wheel robot using hybrid actuation', 2012 IEEE/RSJ International Conference on Intelligent Robots and Systems, IEEE, Vilamoura, Algarve, Portugal, pp.3869-3870, doi: 10.1109/IROS.2012.6386291.

Kress, G. and Winkler, M. (2011) 'Corrugated laminate analysis: a generalized plane-strain problem', Composite Structures, Elsevier Ltd, Vol. 93, No. 5, pp.1493-1504, doi: 10.1016/j. compstruct.2010.12.004.

Kudva, J.N. (2004) 'Overview of the DARPA smart wing project', Journal of Intelligent Material Systems and Structures, Vol. 15, No. 4, pp.261-267, doi: 10.1177/1045389X04042796.

Kumaresh, G., Joerg, M. and Lich, T. (2019) 'Comprehensive study on crashes with pedestrians on Indian roads', SAE Technical Paper Series 1, doi: 10.4271/2019-26-0004.

Lagoudas, D.C. (2008) 'Shape memory alloys', in Otsuka, K. and Wayman, C.M. (Eds.): Shape Memory Materials, Cambridge University Press, Cambridge, Vol. 1, pp.49-96, doi: 10.1007/ 978-0-387-47685-8.

Lawall, J., Morris, S., McQueen, D., Alexander, P., Johnson, N., Browne, A. and Mankame, N. (2009) Adjustable Seat Ramp Utilizing Active Material Actuation.

Lederlé, S. (2002) 'Issues in the design of shape memory alloy actuators', MIT, p.96.

Lee, D.W., Ma, Z-D. and Kikuchi, N. (2010) 'An innovative I-bumper concept for improved crashworthiness of military and commercial vehicles', SAE Technical Paper Series, Vol. 1, No. 724, pp.776-790, doi: 10.4271/2008-01-0512.

Lendlein, A. and Kelch, S. (n.d.) Shape-Memory Effect, doi: 1433-7851/02/4112-2035.

Leng, J., Lan, X., Liu, Y. and Du, S. (2011) 'Shape-memory polymers and their composites: stimulus methods and applications', Progress in Materials Science, Elsevier Ltd, Vol. 56, No. 7, pp.1077-1135, doi: 10.1016/j.pmatsci.2011.03.001.

Liu, C., Qin, H. and Mather, P.T. (2007) 'Review of progress in shape-memory polymers', Journal of Materials Chemistry, Vol. 17, No. 16, pp.1543-1558, doi: 10.1039/b615954k.

Liu, Y., Lv, H., Lan, X., Leng, J. and Du, S. (2009) 'Review of electro-active shape-memory polymer composite', Composites Science and Technology, Elsevier Ltd, Vol. 69, No. 13, pp.2064-2068, doi: 10.1016/j.compscitech.2008.08.016. 
Lu, H., Yu, K., Sun, S., Liu, Y. and Leng, J. (2010) 'Mechanical and shape-memory behavior of shape-memory polymer composites with hybrid fillers', Polymer International, Vol. 59, No. 6, pp.766-771, doi: 10.1002/pi.2785.

Marchese, A.D., Onal, C.D. and Rus, D. (2014) 'Autonomous soft robotic fish capable of escape maneuvers using fluidic elastomer actuators', Soft Robotics, Vol. 1, No. 1, pp.75-87, doi: 10.1089/soro.2013.0009.

Mat Yazik, M.H. and Sultan, M.T.H. (2019) 'Shape memory polymer and its composites as morphing materials', Failure Analysis in Biocomposites, Fibre-Reinforced Composites and Hybrid Composites, Elsevier Ltd, doi: 10.1016/B978-0-08-102293-1.00009-7.

McGowan, A-M.R., Washburn, A.E., Horta, L.G. and Bryant, R.G. (2002) 'Recent results from NASA's morphing project', SPIE's 9th Annual International Symposium on Smart Structures and Materials, Vol. 4698, p.115, doi: 10.1117/12.475056.

McKnight, G. and Henry, C. (2005) 'Variable stiffness materials for reconfigurable surface applications', in Armstrong, W.D. (Ed.): Proceedings Volume 5761, Smart Structures and Materials 2005: Active Materials: Behavior and Mechanics, San Diego, California, USA, p.119, doi: 10.1117/12.601495.

Mehrpouya, M. and Bidsorkhi, H.C. (2017) 'MEMS applications of NiTi based shape memory alloys: a review', Micro and Nanosystems, Vol. 8, No. 2, pp.79-91, doi: 10.2174/187640290 8666161102151453.

Miller, T.F. (2009) Morphing Hull Implementation for Unmanned Underwater Vehicles, May, pp.1-10, doi: 10.1111/j.1471-4159.2004.02444.x.

Mizokami, K. (2018) DARPA Invents Wheels That Instantly Morph Into Triangular Tank Tracks, Available at: https://www.popularmechanics.com/military/a21932118/darpa-wheels-becometank-tracks/\#: :text=DARPA Invents Wheels That Instantly Morph Into Triangular Tank Tracks,-Jun 25\%2C 2018\&text=DARPA\%2C the Pentagon's mad science, to come to a stop. (Accessed 3 May, 2019).

Moffett, M.B., Wun-Fogle, M., Teter, J.P., Lindberg, J.F., Clark, A.E. and McLaughlin, E.A. (2005) 'Characterization of terfenol-D for magnetostrictive transducers', The Journal of the Acoustical Society of America, Vol. 87, No. S1, pp.S95-S95, doi: 10.1121/1.2028440.

Molinari, G. (2016) Multidisciplinary Optimization of Morphing Wings with Distributed Compliance and Smart Actuation, Doctoral Thesis, doi: 10.3929/ethz-a-010782581.

Monner, H., Riemenschneider, J., Opitz, S. and Schulz, M. (2011) 'Development of active twist rotors at the German aerospace center (DLR)', Proceedings of the 52nd AIAA/ASME/ASCE/AHS/ASC Structures, Structural Dynamics and Materials Conference, April, pp.1-10, doi: 10.2514/6.2011-1824.

Monner, H.P. (2001) 'Realization of an optimized wing camber by using form variable flap structures', Aerospace Science and Technology, Vol. 5, No. 7, pp.445-455, doi: 10.1016/ S1270-9638(01)01118-X.

Murray, G., Gandhi, F. and Bakis, C. (2010) 'Flexible matrix composite skins for one-dimensional wing morphing', Journal of Intelligent Material Systems and Structures, Vol. 21, No. 17, pp.1771-1781, doi: 10.1177/1045389X10369719.

Murugan, S., Saavedra Flores, E.I., Friswell, M.I. and Adhikari, S. (2011) 'Optimal design of elastomer composites for morphing skins', ASME 2011 Conference on Smart Materials, Adaptive Structures and Intelligent Systems, ASMEDC, Scottsdale, Arizona, USA, Vol. 1, pp.551-560, doi: 10.1115/SMASIS2011-5021.

Ochoński, W. (2010) 'Application of shape memory materials in fluid sealing technology', Industrial Lubrication and Tribology, Vol. 62, No. 2, pp.99-110, doi: 10.1108/ 00368791011025647.

Oehler, S.D., Hartl, D.J., Lopez, R., Malak, R.J. and Lagoudas, D.C. (2012) 'Design optimization and uncertainty analysis of SMA morphing structures', Smart Materials and Structures, Vol. 21, No. 9, doi: 10.1088/0964-1726/21/9/094016. 
Olympio, K.R. and Gandhi, F. (2010) 'Flexible skins for morphing aircraft using cellular honeycomb cores', Journal of Intelligent Material Systems and Structures, Vol. 21, No. 17, pp.1719-1735, doi: 10.1177/1045389X09350331.

Pagitz, M. and Bold, J. (2013) 'Shape-changing shell-like structures', Bioinspiration and Biomimetics, Vol. 8, No. 1, doi: 10.1088/1748-3182/8/1/016010.

Pendleton, E., Griffin, K., Kehoe, M. and Perry, B. (2013) A Flight Research Program for Active Aeroelastic Wing Technology, pp.2263-2273, doi: 10.2514/6.1996-1574.

Perkins, D., Reed, J. and Havens, E. (2004) 'Morphing wing structures for loitering air vehicles', 45th AIAA/ASME/ASCE/AHS/ASC Structures, Structural Dynamics and Materials Conference, April, doi: 10.2514/6.2004-1888.

Pfeifer, C. (2014) Evolution of Active Grille Shutters, SAE Technical Paper 2014-01-0633, 2014, 1 April. doi: 10.4271/2014-01-0633.

Philen, M.K., Shan, Y., Prakash, P., Wang, K.W., Rahn, C.D., Zydney, A.L. and Bakis, C.E. (2007) 'Fibrillar network adaptive structure with ion-transport actuation', Journal of Intelligent Material Systems and Structures, Vol. 18, No. 4, pp.323-334, doi: 10.1177/ 1045389X06066097tions.

Radice, J., Strom, K.A., Brei, D., Young, J.R. and Luntz, J.E. (2007) 'Modeling and sensitivity study of the dual-chamber SMART (SMA reseTtable) lift device', Modeling, Signal Processing, and Control for Smart Structures 2007, Vol. 6523, p.652305, doi: 10.1117/12.715723.

Ramrakhyani, D.S., Lesieutre, G.A., Frecker, M.I. and Bharti, S. (2005) 'Aircraft structural morphing using tendon-actuated compliant cellular trusses', Journal of Aircraft, Vol. 42, No. 6, pp.1614-1620, doi: 10.2514/1.9984.

Reed Jr., J.L., Hemmelgarn, C.D., Pelley, B.M. and Havens, E. (2005) 'Adaptive wing structures', Vol. 5762, p.132, doi: $10.1117 / 12.599922$.

Reich, G. and Sanders, B. (2007) 'Introduction to morphing aircraft research', Journal of Aircraft, Vol. 44, No. 4, pp.1059-1059, doi: 10.2514/1.28287’.

Reinventing the Automobile: Personal Urban Mobility for the 21st Century (2013) Choice Reviews Online, doi: 10.5860/choice.48-1430.

Rodriguez, J.N., Zhu, C., Duoss, E.B., Wilson, T.S., Spadaccini, C.M. and Lewicki, J.P. (2016) 'Shape-morphing composites with designed micro-architectures', Scientific Reports, Nature Publishing Group, Vol. 6, February, pp.1-10, doi: 10.1038/srep.27933.

Rousseau, I.A. (2008) 'Challenges of shape memory polymers: a review of the progress toward overcoming SMP's limitations', Polymer Engineering and Science, Vol. 48, No. 11, pp.2075-2089, doi: 10.1002/pen.21213.

Rozhdestvensky, K.V. (2006) 'Wing-in-ground effect vehicles', Progress in Aerospace Sciences, Vol. 42, No. 3, pp.211-283, doi: 10.1016/j. paerosci.2006.10.001.

Saadat, S., Salichs, J., Noori, M., Hou, Z., Davoodi, H., Bar-on, I., Suzuki, Y. and Masuda, A. (2002) 'An overview of vibration and seismic applications of niTi shape memory alloy', Smart Materials and Structures, Vol. 11, No. 2, pp.218-229, doi: 10.1088/0964-1726/11/2/305.

Schmitz, A. and Horst, P. (2014) 'Bending deformation limits of corrugated unidirectionally reinforced composites', Composite Structures, Elsevier Ltd, Vol. 107, No. 1, pp.103-111, doi: 10.1016/j. compstruct.2013.07.048.

Schorsch, O., Lühring, A. and Nagel, C. (2016) 'Elastomer-based skin for seamless morphing of adaptive wings', Smart Intelligent Aircraft Structures (SARISTU), Springer International Publishing, Cham, pp.187-197, doi: 10.1007/978-3-319-22413-8_10.

Schorsch, O., Lühring, A., Nagel, C., Pecora, R. and Dimino, I. (2015) 'Polymer based morphing skin for adaptive wings', 7th ECCOMAS Thematic Conference on Smart Structures and Materials, Ponta Delgada, Portugal, pp.1-13. 
Shan, Y., Philen, M.P., Bakis, C.E., Wang, K.W. and Rahn, C.D. (2006) 'Nonlinear-elastic finite axisymmetric deformation of flexible matrix composite membranes under internal pressure and axial force', Composites Science and Technology, Vol. 66, No. 15, pp.3053-3063, doi: 10.1016/j. compscitech.2006.01.002.

Simoneau, C., Terriault, P., Lacasse, S. and Brailovski, V. (2014) 'Adaptive composite panel with embedded SMA actuators: modeling and validation', Mechanics Based Design of Structures and Machines, Vol. 42, No. 2, pp.174-192, doi: 10.1080/15397734.2013.864246.

Song, G., Kelly, B. and Agrawal, B.N. (2000) 'Active position control of a shape memory alloy wire actuated composite beam', Smart Materials and Structures, Vol. 9, No. 5, pp.711-716, doi: 10.1088/0964-1726/9/5/316.

Sreekumar, M., Nagarajan, T. and Singaperumal, M. (2009) 'Application of trained NiTi SMA actuators in a spatial compliant mechanism: experimental investigations', Materials and Design, Elsevier Ltd, Vol. 30, No. 8, pp.3020-3029, doi: 10.1016/j. matdes.2008.12.017.

Stanewsky, E. (2000) 'Aerodynamic benefits of adaptive wing technology', Aerospace Science and Technology, Vol. 4, No. 7, pp.439-452, doi: 10.1016/S1270-9638(00)01069-5.

Sterzelmeier, K., Buderer, G., Ganthier-Blum, C. and Wenning, W. (2003) Electromagnetic Armor Test Facility with Modular Pulsed Power Conceptual Design, pp.1361-1364, doi: $10.1109 /$ ppc.1999.823780.

Straub, F.K. (1996) 'A feasibility study of using smart materials for rotor control', Smart Materials and Structures, Vol. 5, No. 1, pp.1-10, doi: 10.1088/0964-1726/5/1/002.

Strelec, J.K., Lagoudas, D.C., Khan, M.A. and Yen, J. (2003) 'Design and implementation of a shape memory alloy actuated reconfigurable airfoil', Journal of Intelligent Material Systems and Structures, Vol. 14, Nos. 4-5, pp.257-273, doi: 10.1177/1045389X03034687.

Strittmatter, J. and Gü Mpel, P. (2011) 'Long-time stability of ni-ti-shape memory alloys for automotive safety systems', Journal of Materials Engineering and Performance, Vol. 20, Nos. 4-5, pp.506-510, doi: 10.1007/s11665-011-9848-9.

Sufian, S.F., Fairuz, Z.M., Zubair, M., Abdullah, M.Z. and Mohamed, J.J. (2014) 'Thermal analysis of dual piezoelectric fans for cooling multi-LED packages', Microelectronics Reliability, Elsevier Ltd, Vol. 54, No. 8, pp.1534-1543, doi: 10.1016/j. microrel.2014.03.016.

Thangadurai, M., Kumar, R. and Chandra, S. (2018) 'Aerodynamic influence of added surfaces on the performance characteristics of a sports car', Journal of The Institution of Engineers (India): Series C, Springer India, doi: 10.1007/s40032-018-0471-5.

Thill, C., Etches, J., Bond, I., Potter, K. and Weaver, P. (2008) 'Morphing skins', Aeronautical Journal, Vol. 112, No. 1129, pp.117-139, doi: 10.1017/S0001924000002062.

Thill, C., Etches, J.A., Bond, I.P., Potter, K.D. and Weaver, P.M. (2007) 'Corrugated composite structures for aircraft morphing skin applications corrugated composite structures for aircraft morphing skin applications', Carleton University - 18th International Conference on Adaptive Structures and Technologies, ICAST 2007, Ottawa, Ontario, Canada.

Thurnherr, C., Ruppen, L., Brändli, S., Franceschi, C.M., Kress, G. and Ermanni, P. (2017) 'Stiffness analysis of corrugated laminates under large deformation', Composite Structures, Vol. 160, pp.457-467, doi: 10.1016/j. compstruct.2016.10.079.

Tsoi, K.A., Schrooten, J., Zheng, Y. and Stalmans, R. (2004) 'Part, I.I. thermomechanical characteristics of shape memory alloy composites', Materials Science and Engineering A, Vol. 368, Nos. 1-2, pp.299-310, doi: 10.1016/j. msea.2003.11.007.

Tupper, M., Munshi, N., Beavers, F., Meink, T., Gall, K. and Mikulas, M. (2001) 'Developments in elastic memory composite materials for spacecraft deployable structures', IEEE Aerospace Conference Proceedings, Vol. 5, pp.52541-52548, doi: 10.1109/AERO.2001.931215.

Van Humbeeck, J. (2001) 'Shape memory alloys: a material and a technology', Advanced Engineering Materials, No. 11, pp.837-850, doi: 10.1002/1527- 2648(200111)3:11<837 ::AID-ADEM837>3.0.CO;2-0. 
Vincent, J.F.V. (2000) 'Deployable structures in nature: potential for biomimicking', Proceedings of the Institution of Mechanical Engineers, Part C: Journal of Mechanical Engineering, Vol. 214, No. 1, pp.1-10, doi: 10.1177/095440620021400101.

Vokoun, D., Sysel, P., Heller, L., Kadeřávek, L., Svatuška, M., Goryczka, T., Kafka, V. and Šittner, P. (2016) 'NiTi-polyimide composites prepared using thermal imidization process', Journal of Materials Engineering and Performance, Vol. 25, No. 5, pp.1993-1999, doi: 10.1007/s11665-016-2019-2.

Wei, Z.G., Sandström, R. and Miyazaki, S. (1998) 'Shape memory materials and hybrid composites for smart systems - part II shape-memory hybrid composites', Journal of Materials Science, Vol. 33, No. 15, pp.3763-3783, doi: 10.1023/A: 1004674630156.

Weisshaar, T.A. (2013) 'Morphing aircraft systems: historical perspectives and future challenges', Journal of Aircraft, Vol. 50, No. 2, pp.337-353, doi: 10.2514/1.C031456.

Winkler, M. and Kress, G. (2010) 'Deformation limits for corrugated cross-ply laminates', Composite Structures, Elsevier Ltd, Vol. 92, No. 6, pp.1458-1468, doi: 10.1016/j. compstruct. 2009.11.015.

Wlezien, R., Horner, G., McGowan, A., Padula, S., Scott, M., Silcox, R. and Simpson, J. (1998) 'The aircraft morphing program', 39th AIAA/ASME/ASCE/AHS/ASC Structures, Structural Dynamics, and Materials Conference and Exhibit, American Institute of Aeronautics and Astronautics, Reston, Virginia, doi: 10.2514/6.1998-1927.

Wood, K., Brown, T., Rogowski, R. and Jensen, B. (2000) 'Fiber optic sensors for health monitoring of morphing airframes: I.I. chemical sensing using optical fibers with Bragg gratings', Smart Materials and Structures, Vol. 9, No. 2, pp.170-174, doi: 10.1088/09641726/9/2/307.

Wordley, S. and Saunders, J. (2006) Aerodynamics for Formula SAE: A Numerical, Wind Tunnel and On-Track Study, SAE Technical Paper Series, doi: 10.4271/2006-01-0808.

Yokozeki, T., Takeda, S. ichi, Ogasawara, T. and Ishikawa, T. (2006) 'Mechanical properties of corrugated composites for candidate materials of flexible wing structures', Composites Part A: Applied Science and Manufacturing, Vol. 37, No. 10, pp.1578-1586, doi: 10.1016/j. compositesa.2005.10.015.

Yu, K., Yin, W., Sun, S., Liu, Y. and Leng, J. (2009) 'Design and analysis of morphing wing based on SMP composite', in Henderson, B.K. and McMickell, M.B. (Eds.): Proc. SPIE 7290, Industrial and Commercial Applications of Smart Structures Technologies 2009, 31 March, 2009, p.72900S, doi: 10.1117/12.815712

Zand B., Butalia, T.S., Wolfe, W.E. and Schoeppner, G.A. (2012) 'A strain energy based failure criterion for nonlinear analysis of composite laminates subjected to triaxial loading', Journal of Composite Materials, Vol. 6, Nos. 19-20, pp.2515-2537, doi: 10.1177/0021998312449891.

Zhang, X., Toet, W. and Zerihan, J. (2006) 'Ground effect aerodynamics of of race cars', Annual Review of Fluid Mechanics, Vol. 38, No. 1, pp.27-63, doi: 10.1146/annurev.fluid.38. 050304.092016.

Zhang, Z. and Philen, M. (2012) 'Pressurized artificial muscles', Journal of Intelligent Material Systems and Structures, Vol. 23, No. 3, pp.255-268, doi: 10.1177/1045389X11420592.

Zhou, J., Guan, Z.W. and Cantwell, W.J. (2016) 'Scaling effects in the mechanical response of sandwich structures based on corrugated composite cores', Composites Part B: Engineering, Elsevier Ltd, Vol. 93, pp.88-96, doi: 10.1016/j. compositesb.2016.02.061. 
Zhou, Y., Xu, G., Qin, F., Xu, K., Wang, G., Ou, Y., Lin, G. and Zhang, Q. (2013) 'The prospect of smart cars: intelligent structure and human-machine interaction', 2013 IEEE International Conference on Robotics and Biomimetics, ROBIO. 2013, December, pp.1899-1904, doi: 10.1109/ROBIO.2013.6739746.

Zubair, M., Fairuz, Z.M., Sufian, S.F., Abdul Aziz, M.S. and Abdullah, M.Z. (2013) 'Effect of piezoelectric fan mode shape on the heat transfer characteristics', International Communications in Heat and Mass Transfer, Vol. 52, pp.140-151, doi: 10.1016/j. icheatmasstransfer.2013.11.013. 